\title{
LA NOCIÓN DEL NO ENTE EN LA FILOSOFIA DE PARMÉNIDES ${ }^{\circ}$
}

1. El más antiguo filósofo griego del que poseemos fragmentos auténticos, Anaximandro, ha sido el primero en hablarnos de $\tau \dot{\alpha}$ öv $\tau \alpha$, esto es, de las cosas de la percepción sensible, de los entes que se nos dan aquí y ahora, a nuestro alcance inmediato, y ha sido el primero en dejar constancia directa de una teoría de la génesis, corrupción y principio de ellas. El hecho tiene para nosotros una considerable importancia, no tanto por lo que atañe a la teoría en sí, cuanto por esos objetos perceptibles sobre los que versa. Es indudable, como lo ha mostrado Jaeger en nuestros días, que el término usado para designarlos ha debido pertenecer al vocabulario de estos primitivos naturalistas milesios. ${ }^{1}$ En realidad, es posible encontrarlo ya en Homero y Hesíodo, revestido de un sentido altamente revelador. En efecto, $\tau \grave{\alpha}$ őv $\tau \alpha$, si atendemos

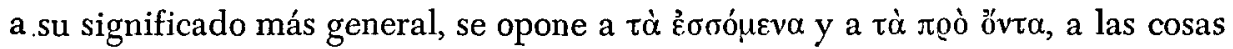
que serán en el futuro y a las que fueron en el pasado. Sin embargo, este sentido de presencia que arrastra el término habrá de matizarse aún más, gracias a esa nueva actitud de pensamiento que es entonces la filosofía naciente, la cual va a convertirlo en el objeto de sus inquisiciones. En adelante, ese sentido no se mantendrá única y exclusivamente en el terreno temporal; antes bien, su ámbito se ensancha hasta abarcar todo el mundo circundante de la experiencia humana. Adviértase, además, que la generación y la corrupción, el cambio en general, no han sido aún desterrados de este mundo de $\tau \dot{\alpha}$ ôv $\alpha$. Las cosas o los entes con que se enfrentan los pensadores preparmenídeos conservan todas sus características de entes de un mundo cambiante y mudadizo; pero de un mundo que ha dejado de ser puramente mítico, alejado de la

- El presente trabajo será el capítulo de una obra titulada La noción del no ser en la filosofía griega. De Parménides a Aristóteles, que el autor prepara bajo la dirección del Dr. Eduardo Nicol y la cual presentará como tesis para la obtención de Grado Académico en la Facultad de Filosofía de la Universidad Nacional Autónoma de México. Como quiera que la investigación está en curso todavía, el texto que aquí se presenta no tiene el carácter de una versión definitiva, y ha de ser considerado como el resultado primero, sujeto a revisión, de una investigación sobre la filosofía de Parménides; algunos de sus puntos, además, dependen de otros que habrán de tratarse en diferentes capítulos, dentro del plan general de desarrollo. El hecho de que el texto que ahora se publica revele alguna discrepancia de enfoque o interpretación, y hasta de terminología, respecto de los criterios adoptados por el Dr. Nicol en sus publicaciones y su Seminario, es un hecho que considero necesario indicar, lo mismo para dejar a salvo su respo"sabilidad, como director de mi tesis, que para agradecer la autonomía de que he gozado para desarrollar la investigación.

1 W. Jaeger, La teologia de los primeros filósofos griegos, trad. esp. de José Gaos, Fondo de Cultura Económica, México, 1952, pp. 24-25. 
experiencia humana, para convertirse en un mundo donde el hombre desenvuelve sus afanes, sean especulativos o prácticos, con estrecho contacto con las cosas. El salto de un tipo de pensamiento a otro se ha verificado. La

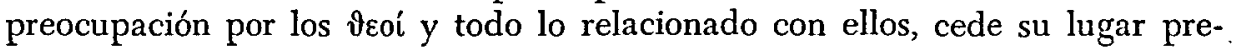
ponderante a la preocupación por $\tau \dot{\alpha}$ övta, por esas cosas que se encuentran presentes en ese mundo experimentable y no fuera de él.

Parécenos que esto torna muy comprensible la inclusión del término $\tau \grave{\alpha}$ ה̈v $\alpha$ dentro del primer fragmento de Anaximandro. Sin embargo, algunos intérpretes del pensamiento griego, entre ellos Burnet, ${ }^{2}$ han expresado ciertas dudas acerca de la legitimidad de tal inclusión. De hecho, no hay razón alguna para suponer que ello sea un anacronismo. Tal término no ha tenido un rango estrictamente metafísico desde que ocupó un sitio en el léxico filosófico. Para ello hará falta justamente el especial tratamiento del ente en cuanto ente y su expresión en el Logos. Semejante tarea la cumplirá Parménides. Pero esta ontología supone un gran avance a partir de los conceptos rudimentarios de los físicos de Mileto. Por ello es erróneo concebir que tò ôv ha significado, desde el momento en que los filósofos han comenzado a servirse de él, algo así como lo que significará posteriormente el platónico ővtws öv. ${ }^{3}$ Visto así, el Ente de Parménides adquiere de inmediato el rango de algo totalmente nuevo, surgido de la pura especulación inteligible. Por lo contrario. es preciso caer en la cuenta de la ingenuidad primera inherente a este concepto, . para poder captar la novedosa posición que adopta el eleata frente a sus predecesores, dentro de la unión estrecha que guarda con ellos.. Pues, como resultado de dicho parecer, ciertos historiadores de la filosofía griega han propendido, y propenden, a dejar un poco en la obscuridad esta conexión entre el pensamiento positivo de Parménides y todo el pensamiento anterior, para no atender casi más que a lo que de contrapuesto hay entre ellos. Pareja actitud tiende a ocultar el verdadero punto de partida de la especulación parnenídea, que, en substancia, no viene a ser otro que el de un Anaximandro, para citar un ejemplo. ${ }^{4}$ En efecto, tanto el milesio como el eleata pretenden teorizar sobre los entes. Que en un caso esto lleve a negar precisamente la multiplicidad y variedad de ellos, eso no vendrá a constituir otra cosa más que el resultado de esa investigación teórica y no la negación de una misma y común raíz. El hecho no debe desorientarnos. Incluso la misma investigación, a pesar de sus logros tan diametralmente opuestos en uno y en otro, ha obedecido también a una misma temática, como tendremos ocasión de comprobarlo, n. 6.

2 J. Burnet, Early greek philosophy, Adam and Charles Black, London, 1952, p. 52,

3 Ya en la antigüedad encontramos en Simplicio, phys., 22, 22 (Jenófanes A 31): oủ

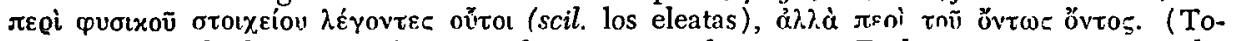
das las citas de los presocráticos se hacen con referencia a Diels-Kranz, Die Frag. der Vors., Weidmannsche Verlagsbuchhandlung, $7^{\text {a }}$ ed., Berlin, 1954).

4 Tocante a las relaciones entre Parménides y Anaximandro, puede verse J. Stenzel, Metaphysik des Altertums, München und Berlín, 1931, págs. 46 sigs. 
aunque indudablemente presente aspectos metódicos más complejos en Parménides que en Anaximandro.

Esta complejidad precisamente es lo que ha permitido una mayor penetración en la realidad. Si Parménides llega a resultados que ponen en entredicho los frutos de todo el filosofar ya efectuado previamente y se oponen tajantemente a la circunstancia entera en la que hubo de moverse, se debe lisa y Ilanamente a la elección de un nuevo y distinto camino para acceder a ellos. Puesto en marcha, el eleata contestará a preguntas similares a las que asediaban a sus precursores y contemporáneos, así sea para darles en su mayor parte una respuesta negativa. Pero su mirada no se detiene aquí. El afán de explicar la realidad en su conjunto lo lleva a elaborar la primera gran explicación sistemática del error humano, para mostrar dónde radica la equivocación esencial y la fuente de la aparente verdad de todas las concepciones del mundo insertadas en esa su circunstancia. Todo ello revela hasta qué punto Parménides ha tomado en cuenta el pensamiento de su tiempo, y hasta qué punto constituye una falta de perspectiva el verlo circundado con un aire de novedad tal que lo hace parecer completamente extraño al mundo griego de aquellos siglos.

2. Parménides se nos presenta como el primer filósofo que ha cobrado . conciencia de su proceder metódico. Su camino (óó́s) no es más que la prefiguración más viva y cálida de lo que más tarde iba a recibir precisamente el frío nombre de método ( $\mu \varepsilon^{\ddots} \vartheta_{0} \delta_{0}$ ). Por lo pronto, trátase de algo muy personal; de algo comparable a la revelación divina y que recuerda ciertamente el tono de los poemas apocalípticos del siglo vi a. c. No vamos a discutir aquí el grado de autenticidad piadosa que se encierra en tamaña revelación. Nosotros no creemos que haya ninguna, a pesar de la gran cantidad de ingredientes religiosos tomados de la tradición que en ella entran. ${ }^{5}$ Es este descubrimiento de una nueva vía, de un nuevo tipo de pensamiento, de la razón, lo que impregna el Poema, y especialmente su Proemio, de ese pathos tan extraordinario que, en ocasiones, tiende a confundirse con un sentimiento de un

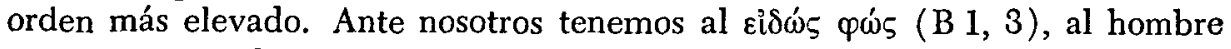

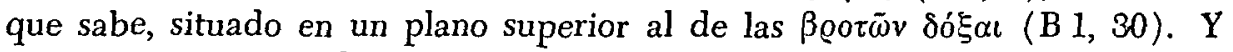
es muy significativa la elección de la palabra. $\phi \dot{\omega} 5$, como se sabe, ha sido usado en la poesía antigua, en Homero especialmente, con la acepción de héroe o de hombre de alto rango. ${ }^{6}$ En cambio, los hombres que viven en la opinión, los mortales, nunca son designados con esa palabra por Parménides.

5 Para una discusión del asunto, véase P. Albertelli, Gli eleati, Laterza, Bari, 1939, págs. 120-122.

6 Hom., $I l ., 4$, 194; 5, 572; 17, 377; 21, 545. En Od. 21, 25, encontramos:

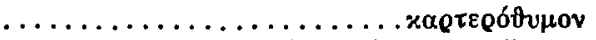

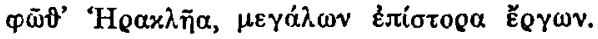


Esto nos recuerda la entonces ya tradicional oposición entre el héroe y el hombre ordinario. Sólo que ahora la areté que distingue al héroe adquiere un nuevo matiz. En Homero, por ejemplo, rara vez la areté mienta cualidades espirituales. ${ }^{7}$ Por lo contrario, la areté de Parménides, en este modo figurado de hablar, radica precisamente en la posesión de la razón, del voeĩv, encuadrado todo esto en una jerarquía que va del no saber absoluto a la razón, pasando por la opinión engañosa. De esta manera se aclara el sentido que para Parménides tiene esa vía de la verdad, que hasta cierto punto podría ser calificada, tal como lo hace Jaeger, de vía de la "salvación"; pero sólo si entendemos "salvación" como salvación, por medio de la verdad inmutable, frente a la apariencia y el engaño. La búsqueda de la verdad, según lo indica el simbolismo del Proemio, es comparable a la actividad piadosa; pero la verdad que descubre el eleata no está de ningún modo animada por la fe religiosa. ${ }^{8}$

Parménides va a proclamar la verdad sobre el Ente, que es al mismo tiempo la negación de su multiplicidad. Este hallazgo lo distingue claramente de Ios pensadores que lo antecedieron. La meditación sobre $\tau \dot{\alpha}$ őv $v \alpha$ resulta ser en verdad una meditación sobre tò ơv. Los dos aspectos ineludibles que presenta toda doctrina filosófica se nos ofrecen aquí con una gran claridad. Algo semejante encontramos ya en Jenófanes y Heráclito. Pero en Parménides, estas tareas, una constructiva y la otra destructiva, se ligan íntimamente a una claboración del concepto de verdad que es enteramente nueva. Se ha reconocido suficientemente que Hesíodo ha sido el primero en darle a este concepto un uso que en mucho anticipa al de Parménides, pero sin ir más allá. ${ }^{9}$ El eleata sabe que la verdad, para ser verdaderamente tal, requiere necesariamente ser incambiable, inmutable $y$, en tal sentido, única. Por eso nos hablará justamente del "corazón inmutable de la verdad bien rotunda", de su asiento invariable. ${ }^{10}$ Lo cual, dentro de la concepción parmenídea del tiempo, equivale a considerarla de un modo eterno, como observaremos más adelante a propósito de tò ôv. De aquí también que siempre veamos oponerse esa verdad una a las variadas opiniones de los hombres, como lo único en que se puede confiar; lo seguro y digno de crédito o creencia, all par que lo evidente. No otra cosa significa esa jiotios i $\alpha$ v́s (B 8, 12) de que nos habla el eleata. ${ }^{11}$

Cabe, entonces, la pregunta: ¿por qué no todos comulgan con ella, por qué

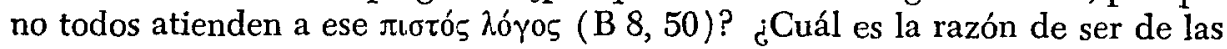

7 Sobre esto, véase W. Jaeger, Paideia, I, trad. esp. de J. Xirau, Fondo de Cultura Económica, México, 1942; p. 22.

$\checkmark$ Cf. F. M. Cornford, Plato and Parmenides, Routledge and Kegan Paul, London, 1950 ; págs. $28-29$.

9 Hes., Teog.; 27. CF. Wilhelm Luther, Wahrheit und Lïge im ältesten Griechentum, Borna und Leipzig, 1935; págs. 121 sigs. Véase también H. Diels, Parmenides Lehrgedicht, G. Reimer, Berlin, 1897; p. 10.

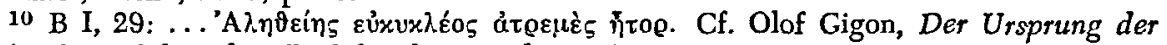
griechischen Philosophie, B. Schwabe, Basel, 1945, p. 249.

11 Cf. B I, 30. 
opiniones? Parménides comparte el parecer de Sófocles acerca de que ßootw̃u... $\pi ı \sigma$ Tỗv oủdév. ${ }^{12}$ Pero ¿qué motivos hay para que ello sea así? Lo que sucede es, por lo pronto, que tenemos que vérnoslas con otra fuerza ( $\left.\beta^{\prime} \alpha\right)$ antagónica de la anterior. Hay algo que nos fuerza o constriñe ( $\beta \beta^{\prime} \alpha \zeta \varepsilon l$ ) a entrar en el camino de la opinión, un cierto hábito que desorienta: el hábito de las múlti-

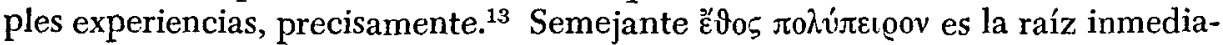
ta de ese peligroso mundo de la $\delta o ́ \xi \alpha$. Pues, en efecto, su peligro estriba en esa engañadora violencia con que se nos impone y que le es consubstancial. ${ }^{14}$ Debido a ello, y en tanto que es la forma del conocer humano, no es muy aventurado asegurar que en esa medida reviste una cierta necesidad y potencia. ${ }^{15}$ Esto aclara el porqué de la violenta diatriba de Parménides contra los sentidos y los mortales que nada saben. ${ }^{16}$ En realidad, los sentidos son un puro engaño. Los ojos, en verdad, son ciegos; los oídos y lengua, zumbantes (B 7, 4-5). Tanto el conocimiento empírico, como el conocimiento de oídas, recibido de la tradición, son rechazados, pues, enérgicamente. Creyendo ver, son ciegos los mortales; creyendo oír, sordos. La verdad se nos revela así como algo totalmente desconectado de los sentidos. El único medio para acceder a ella es la razón, a lo largo de una dura pugna contra la falaz fuerza de los sentidos. ${ }^{17}$

Esta verdad inmutable, ajena a lo sensible, es al par y por lo mismo la verdad sobre el Ente. La Vía de la verdad partirá del principio siguiente: que es y que no (le) es posible no ser. ${ }^{18}$ Aquí el sujeto de la oración es evidentemente tò ơv. ${ }^{19} \mathrm{La}$ verdad primigenia encierra, como se ve, una doble afirmación $o$, si se quiere, una afirmación y una negación. Por una parte, se

12 Sófocles, Frag. 583.

13 B 7, 3.

14 Erróneo parece, pues, el comentario de J. Zafiropulo, L'École éléate, Les Belles

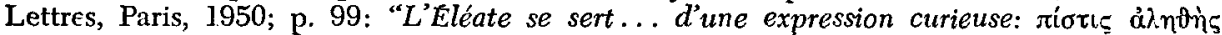

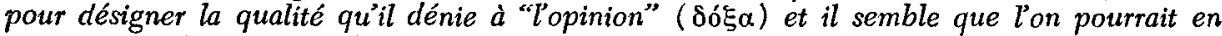
inferer que s'il refuse la "croyance véritable" il ne lui refuse pourtant pas la "croyance" tout court. Aux deux genres de connaissance correspondent deux genres de croyance, chacune valable dans son domaine."

15 Cf. Olof Gigon, op. cit., p. 248.

16 B 6, 4. Por lo que toca al problema de la identificación de estos "mortales", creemos que no hay una razón decisiva para no aceptar el punto de vista de Reinhardt, adoptado también por Cornford, Friedlander y Jaeger entre otros, quienes los identifican con la raza entera de los mortales de que nos habla el Proemio, tanto como la segunda parte del Poema. Los argumentos en pro de esta interpretación los veremos más adelante con mayor detalle.

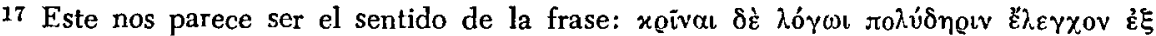

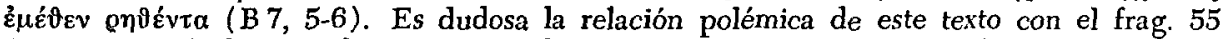
(13, Bywater) de Heráclito. a menos de suponer que Parménides aluda directamente a Heráclito en B 6. Véase $n .16$.

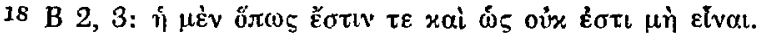

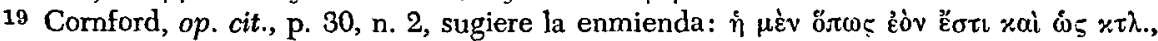

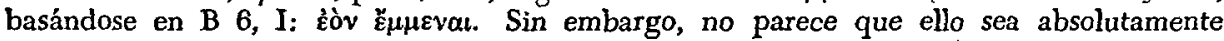
necesario. 
explicita afirmando que el ente es; por otra, negando toda posibilidad de que no sea, de que no haya sido o de que deje de ser. $^{20}$ Lo que es existe, se afirma: no fué ni será, sino que es. ${ }^{21}$ Nada más evidente, en efecto. Nada más verdadero. De lo contrario, tendríamos que admitir que lo que es no es ahora, sino que fué o será en el futuro. Si en esto consistiera todo el problema no habría nada que agregar. Pero ello no es así. La dificultad yace en las complicaciones que introduce el segundo miembro de esta verdad. Parménides necesitará probar exhaustivamente, mediante una revisión de los conceptos de su época, que en realidad no hay ninguna posibilidad de que el ente que ahora es haya podido no ser en el pasado o pueda dejar de ser en el futuro, o, para decirlo con otras palabras, que pueda generarse o perecer. En cuanto a pensar que ahora no sea, eso constituye algo totalmente opuesto a la verdad $y$, por ende, una segunda Vía, totalmente inverosímil de suyo, que halla su expresión en el juicio siguiente: que no es y que necesario (le) es no ser. ${ }^{22}$ Por tanto, esta Vía no presenta de hecho ningún serio problema. Que lo que es no sea, y que ello se presente como algo actual, real y necesario, y ya no como algo meramente posible, sea antes o después, se nos muestra como algo

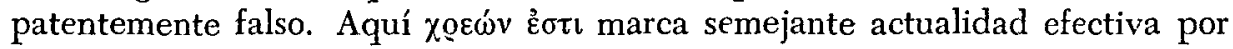

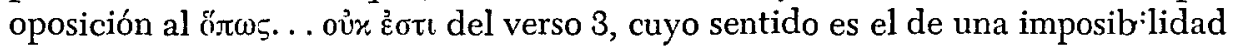
absoluta. ${ }^{23}$ En concordancia, el procedimiento para refutar las posibilidades de que el ente no haya sido o pueda dejar de ser consistirá en tratar de reducirlas a este camino absurdo y falso, mostrando que ambas, en último resultado, implican lo absolutamente imposible, una actualización o realización efectiva de la inexistencia del ente, disfrazada con la admisión de su existencia. La dificultad y necesidad de tal tarea obedecen al hecho de que tales posibilidades se presentan como algo verosímil para la opinión humana. Una vez más

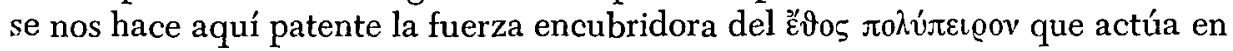
el fondo de las opiniones y contra el cual tiene que luchar la verdad. En cambio, la vía falsa. la vía del no ente, es totalmente inexplorable, impracticable para todos. ${ }^{24}$ Pues su aceptación equivale a la aceptación de lo impensable, inexpresable y sin sentido, a la admisión de que lo que es no es, del no ente. ${ }^{25}$

20 Semejante negación viene a negar, en efecto, toda posible inexistencia del ente, ya sea en el pasado, en el presente o en el futuro. La dificultad estriba en una posible inexistencia en el pasado o en el futuro, a pesar de la existencia presente.

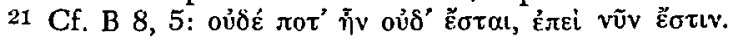

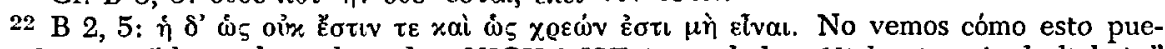
da traducirse: "der andere aber, dass NICHT IST ist und dass Nichtsein erforderlich ist" (Diels-Kranz, 7a ed.).

23 No estamos de acuerdo con la traducción de Albertelli, op. cit., p. 131: “' l'altra (che dice) che non è $e$ che non è possibile che non sia", ni con su interpretación de este verso, p. 131, n. 4: "Intendi: che dice che in qualche momento del tempo non è che non e possibile che in qualche momento del tempo non sia."

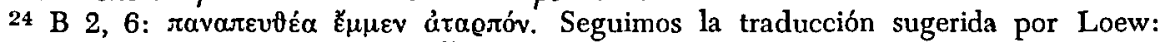

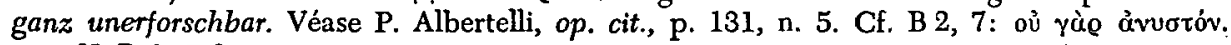
25 B 2, 7-8. 
En este punto es donde se intenta, por primera vez en la historia de la filosofía griega, un especial tratamiento del no ente. Pero adviértase que Farménides no nos habla de un abstracto no ser, sino de algo, por así decirlo, más palpable, en cuanto es la negación radical de un ente aún muy concreto, con propiedades muy determinadas. Ahora bien, este peculiar tratamiento del no ente determina una concepción del mundo en su totalidad. Y ya veremos cómo, para tratar de substituirla o negarla, será menester justamente darle un nuevo tratamiento a esta noción de lo que no es: transformarla o, como en el caso de Gorgias, aniquilarla. Por otra parte, revisando los particulares "atributos" del ente, se tornará clara su condicionalidad en relación a dicha noción; ya que cualquier negación de ellos tiene por consecuencia inmediata una aceptación de tò $\mu$ ì őv. Probablemente el ejemplo más palpable nos lo presenta la fundamental característica de unidad que Parménides descubre. Pero es igualmente factible comprobar tal condicionamiento en todos los aspectos del pensamiento del eleata. Principalmente en su parte crítica, dado que el no ente viene a ser la instancia última que prueba la falsedad, el sin sentido, de las otras doctrinas filosóficas, a la vez que entrega una garantía de certeza para la eleática. Esto quiere decir que la postura entera de Parménides depende, en último resultado, de la oposición de dos factores, enlazados y delimitados mutuamente. El uno aclarará al otro y viceversa. La noción de no ente constituye el segundo plano sobre el cual se perfila nítidamente todo el cerrado y extraordinario mundo de la verdad parmenídea.

3. La alternativa entre ente y no ente es, principalmente por lo que toca al conocer, fundamental. A partir de tal alternativa se abren las dos grandes vías de la verdad y del no ente. Pero todavía hay, como vimos, una tercera posibilidad: admitir tanto el ente como el no ente. Esta tercera vía es, de hecho, tan inadmisible como la última de las anteriores; pues sólo el ente puede ser pensado, conocido. El no ente no lo puede. Pensar es pensar lo que existe, lo que es. ${ }^{26}$ En este sentido, el pensar es siempre un pensar recto, verdadero, que excluye todo error. ${ }^{27}$ En ello radica precisamente su necesidad, su cualidad de ley justa, no arbitraria, basada en la necesidad ínsita en el ente mismo. ${ }^{28}$ Es fácil verlo. Que el ente, explicitado en sus diversos atributos, sea, no ofrece ninguna duda; es algo necesario. Del mismo modo, pensar que el ente existe, se nos presenta como algo igualmente ineludible y necesario. ${ }^{20}$

26 Cf. B 3.

27 La expresión $\pi \lambda a x$ tòv vóov de B 6, 6, tomada en su contexto, es aguda e irónicamente contradictoria en relación con la propia doctrina de Parménides.

28 Cf. B I, 26. En contra de la opinión de Diels, op. cit., p. 54, seguido por Kranz en las últimas ediciones de Die Frag. der Vors., creemos que aquí, dado el carácter simbólico del Proemio, $\Delta i x \eta$, Moị $\alpha$ y Ӫ́xuc, al igual que $\Delta i x \eta$ en B I, 14, deben escribirse con mavúscula. Sobre Moira, Themis y Diké, véase Jaeger, Paideia, I, ed. cit.; págs. 120-121 y $196-197$.

29 Cf. B 6, I. 
Justamente por eso la primera vía, la que sigue a la verdad, es persuasiva dentro de su expresión, exige obediencia semejantemente a una ley divina; lo cual va implícito en el $\Pi \varepsilon ı \vartheta \dot{~ q u e ~ e n c o n t r a m o s ~ e n ~ e l ~ v e r s o ~} 4$ del fragmento $2 .^{30}$ En el fondo, se da una íntima correlación entre el pensar y el existir. Sólo el ente es pensable y sólo lo pensable es ente. El signo distintivo de la realidad es la racionalidad. No otra cosa significan las palabras de Parménides (B 3):

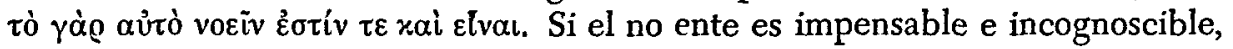
ello quiere decir claramente que no existe; o a la inversa, si no existe, ello significa que no es pensable ni cognoscible. Pero no supongamos que, en virtud de este último hecho, nos veamos en el trance de no poder afirmar ni siquiera que el no ente no existe. Ello no nos conduce más allá de lo cognoscible, sino, por lo contrario, nos guía por su verdadera ruta. ${ }^{31}$ El gran rasgo distintivo de

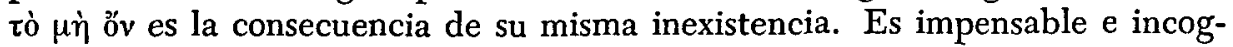
noscible. Consecuentemente, la vía del no ente lo será también de toda necesidad. ${ }^{32}$

Pero, aparte de ésta, Parménides extraerá otras consecuencias del hecho de que sea lo mismo pensar y pensar que el ente es. ${ }^{33}$ Sólo el pensar recto es expresable, pues sólo él da expresión del ente, sólo él puede expresarlo como tal, con estas y aquellas características. Si suprimiéramos el ente, suprimiríamos de golpe el pensamiento; pero, dado que eso no es posible, su expresión debe ser entonces auténtica expresión, manifestación de ese pensamiento. ${ }^{34}$ Enunciar al ente es enunciarlo como tal, como lo que es, fuera de toda contaminación con lo que no es, con el no ente. De otro modo no puede hablarse de expresión, sino de un mero orden engañoso de nombres de mera palabrería vacua y nada más. Con todo, lo anterior no debe entenderse en sentido lógico. No se da una previa reflexión sobre la constitución de los juicios formulados sobre el ente. Parménides está muy lejos de tener una clara conciencia de ello. Sean los juicios que fueren, lo que importa es que enuncien una identidad: la del ente consigo mismo. Si esto puede implicar ciertas consecuencias tocante a su concepción, eso es sólo un modo nuestro de interpretar las cosas y sería enteramente gratuito atribuírselo a Parménides. ${ }^{35}$

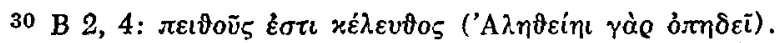

31 Por esta y por otras razones, no podemos estar de acuerdo con Gigon, op. cit., p. 252, cuando afirma: "Nichtseiendes kann nicht gedacht werden. Es kann gar nicht in den Bereich des Denkens fallen. Parmenides sagt nicht etwa (dies ist wichtig), dass das Nichtseiende nicht sei. Das steht jenseits des Wissbaren... Es wird also zunächst nur die Undenkbarkeit des Nichtseienden behauptet, nicht die Nichtexistenz."

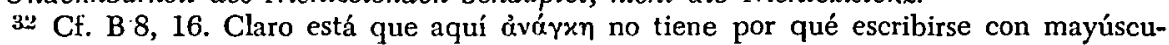
la, supuesto que ya no cae dentro del simbolismo del Proemio. Véase n. 28.

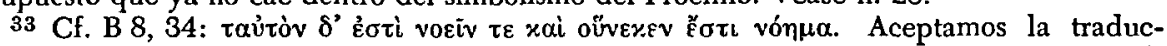
ción de Calogero, Studi sull 'Eleatismo, Tipografia del Senato, Roma, 1932; p. 11: "la stessa cosa è il pensare $e$ il pensiero che è". En efecto, oưvexa no puede entenderse como

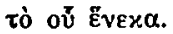

34 Cf. B 8, 35.

35 Tal es la postura de E. Hoffman, Die Sprache und die archaische Logik, Heidelb. 
Sin pensamiento - que en todo caso debe siempre entenderse como pensamiento verdadero- no puede haber legítima expresión. Por consiguiente, cuando nos referimos al no ente, no hacemos otra cosa que pronunciar palabras a las que ningún pensamiento corresponde, desprovistas absolutamente de base; porque ni siquiera las respalda el engaño propio de las opiniones humanas. En éstas, el caso es muy distinto. Admitir la generación, la corrupción, el cambio en general, la multiplicidad, al par que la existencia del ente, parece algo legítimo. Pero, en realidad, si se admiten como algo real, no es posible mantener ya la existencia de lo que es. Por eso, todas estas cosas no vienen a ser, en último resultado, más que meros nombres, a los que nada real corresponde, aunque estén sostenidos en esa mezcolanza de ente y no ente que es la Opinión. La apariencia de verdad que envuelve toda opinión es lo que posibilita el efectivo establecimiento de nombres semejantes, ${ }^{36}$ de acuerdo con el parecer humano. ${ }^{37}$ Los mortales son, en este sentido, verdaderos ỏvouaroлoroí,

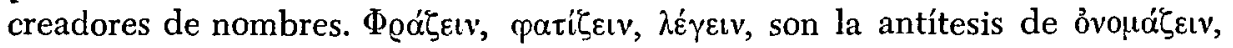
tanto como yvón es antítesis de vóos. Para Parménides hay, pues, por así

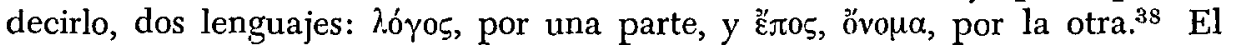
lenguaje de los hombres es una convención que no coincide con el pensamiento verdadero $y$, por ende, con el ente; tan variable como variables son las opiniones humanas. Por otra parte, es fácil caer en la cuenta de que pensamiento y opinión no pueden darse a la vez. O uno o el otro. La alternativa entre ente o no ente se presenta una vez más como condicionante último de toda otra alternativa. Porque eliminada toda la engañadora fuerza de la vía de la opinión, ésta se revela no ser más que la vía del no ente disfrazada. Desenmascarar este tercer camino, mostrarlo como lo que es, tal será el fin que Parménides se propone alcanzar.

En el cumplimiento de dicha tarea es donde se nos hará patente su condicionalidad frente a las tendencias generales de pensamiento de su época. Parménides va a reseguir los grandes temas de su circunstancia, tratando de darles una nueva respuesta dentro de lo posible, aunque sin desprenderse totalmente de algunos de sus presupuestos, como se verá en ciertos puntos referentes a los caracteres del ente. No vamos a entrar ahora en el detalle de la polémica. Por lo pronto nos contentaremos con aclarar sus líneas más generales, persiguiendo la cuestión del convencional "dar nombre" hasta sus últimas consecuencias; porque, en efecto, todo lo que hasta aquí se ha dicho no basta para

Abh. z. Philosophie und ihrer Geschichte, 3, J. C. B. Mohr, Tübingen, 1925, p. 11: “Das Wahrdenken spricht sich... nur im Sein des Logos, in der Identitït des (eleatisch legitimieren) Urteils." Los argumentos de Hoffman en favor de lo anterior, relativos a la pretendida concepción parmenídea de la cópula en el juicio, deben desecharse por el anacronismo que implican.

36 Cf. B 8,38 .

37 Cf. B 8, 53.

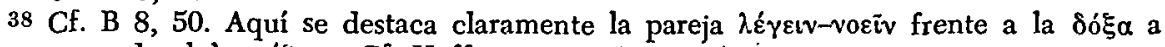
que corresponde el ovouábetv. Cf. Hoffman, op. cit., p. 11. 
acotar definitivamente el sentido de la opinión. Esta no consiste en una mera variedad de palabras sin conexión alguna, aisladas y sin referencia mutua. Muy

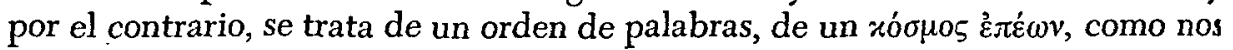
dice Parménides. ${ }^{39}$

Este xóøuo5, este orden de meras palabras, es lo que constituye justamente el mundo de la opinión; un mundo articulado, organizado, sea una forma u otra. Es curioso comprobar cómo tomado xóouos en este sentido, envuelve a la vez el significado de orden y de mundo. En realidad, el mundo de la $\delta o ́ \xi \alpha$ no viene a ser otra cosa que eso, un orden engañoso de nombres. ${ }^{40}$ Sin tal orden no hay mundo semejante. El es ese mundo mismo. Ahora bien, sabemos que sus componentes últimos no son cosas reales, sino palabras únicamente, que hallan una especie de justificación en la sensibilidad. Empero, no conocemos el origen de ese mundo de la apariencia. No sabemos de dónde ha partido y cómo. se ha desarrollado esa trabazón unitaria, ese orden, de tales elementos primigenios.

Como es bien sabido, ese mundo se expone en la segunda parte del Poema. Pero su abordaje es ciertamente complicado. Las más variadas conjeturas se han tejido en torno a su interpretación. Con todo, parece un hecho cierto que no es posible seguirla considerando, según se creyó a partir de Diels, como una suerte de doxografía o recolección de doctrinas muy particulares a las que se venía a oponer la propia de Parménides. El mismo John Burnet, uno de los defensores más significados de este parecer, tuvo que reconocer que en realidad ello no era susceptible de una demostración rigurosa. ${ }^{41} \mathrm{El}$ error de Diels y Burnet consistió en creer que Parménides polemizaba directamente contra ciertos pensadores muy determinados. Pero esto es muy difícil de aceptar dado el carácter mismo del Poema. En efecto, su tono entero, equiparable al tono de la revelación de una Diosa, es muy general y elevado para descender a tales particularidades. El desprecio del eleata se dirige contra la raza entera de los mortales, no contra este o aquel miembro de ella. Desde Willamowitz

39 Cf. B 8, 52 .

40 Es claro que Parménides sólo puede hablar de "mundo" en este sentido; pues, como ya decía Diels, op. cit., p. 66: "nicht 'Welt' heisst xóouos bei den Philosophen aes 5. Jahrh. von Heraklit an. Denn Anaximenes bei Aëtius 1, 3, 4 gibt nicht die Original-

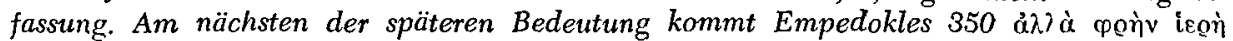

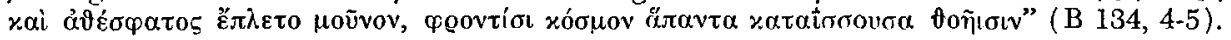

41 J. Burnet, op. cit., p. 185: "The view that the second Part of the poem of Parmenides was a sketch of contemporary Pythagorean cosmology is, doubtless, incapable of rigorous demonstration..." Tannery, Pour l'histoire de la science hellène, Gauthier-Villars, Paris, 2a ed., 1930; p. 233, también ha reconocido que "en tout cas, il est bien clair que l'on n'a pas à considérer sans plus toutes les opinions de Parménide comme pythagoriciennes. Bien loin de là, il faut une critique minutieuse pour discerner sur chacune d'ellos si l'on se trouve bien en présence d'un emprunt authentique fait à l'École, ou, comme l'indique Zeller, d'une réminiscence des poèmes cosmogoniques, d'une théorie venue de l'Ionie, d'une formule que Parménide aura voulu marquer de son sceau personnel". El mismo Stenzel, op. cit., p. 55, 14-16, está aún demasiado influído por esta concepción. 
hasta Jaeger, todos los comentaristas están de acuerdo, en términos generales, con esta apreciación. ${ }^{42}$ Pero a partir de aquí la cuestión vuelve a complicarse con interpretaciones particulares, no muy concordantes entre sí. Sin embargo, el sentido de esta segunda parte no es muy difícil de desentrañar a partir de las bases precedentes. Parménides es un pensador bastante coherente. Una vez que nos ha hablado de los sillares del mundo de la doxa, pasará a mostrarnos cómo ellos se engarzan entre sí y dónde se cimientan. Esto es, pasará a mostrarnos la edificación, el modo de constitución, de tal xóouo

Semejante narración o mostración no será, por consiguiente, la expresión de una determinada y particular concepción del mundo. Parménides pretende hacerla valedera para toda posible construcción de ese tipo. Tal como ya se ha visto, al eleata le parece que toda suerte de opinión se funda en una inadmisible mezcla de ente y no ente, enmascarada por palabras sin base real $y$, en último término, por la engañosa potencia de los sentidos. Teniendo en cuenta esto, será fácil poner al descubierto el mecanismo intrínseco de toda cosmología valedera para los hombres de esa época, trátese o no de filósofos. Consecuentemente, el cuadro que ha de ofrecernos simbolizará el meollo mismo de tales concepciones y, al par, servirá para mostrarnos que éstos sólo pueden darse a partir de algo tan totalmente absurdo como es dicha mezcla. Pues, ciertamente, para el eleata, un mundo donde se incluya el cambio, la genera. ción y la muerte, la multiplicidad, sólo se torna posible a partir de una cierta admisión del no ente. Pero de esto no son conscientes los mortales. Antes bien, su vida entera se desarrolla en el engaño, en la apariencia de verdad que presenta la serie de palabras que constituyen la opinión y que velan la única verdad posible, la verdad sobre el ente. Este otro factor es, pues, también constitutivo del mundo de la opinión. El le da su aire de verosimilitud, el aire de algo real y efectivo. Todo esto es lo que tiende a hacer patente la segunda parte del Poema. El elen.ento agonístico que caracteriza en gran medida al genio griego parece en parte jugar aquí un gran papel. Parménides va a enfrentarnos con un sistema cosmológico que parece verdadero, dejando entrever toda la falsedad que entraña, en relación a su propia doctrina. Demostración más palpable ya no se puede pedir. Con ella culmina toda su teoría de los nombres y palabras convencionales y se da una explicación rotunda de la Opinión. ${ }^{43}$

Esta se inicia con la decisión, por parte de los mortales, de nombrar dos formas elementales, de acuerdo con una apariencia de verdad. ${ }^{44}$ Este es su

42 Véase, por ejemplo, Jaeger, La teol. de los primeros fil. gr., ed. cit., p. 104.

43 Por tal razón, no parece acertada la conclusión de Ueberweg-Praechter, Die Philosophie des Altertums, E.S. Mittler, Tübingen, 1953; 16, p. 87: "Zwischen Sein und Schein fehlt bei ihm die philosophische Vermittlung; die Entstehung eines Scheins ist nicht erklärt und mit dem obersten Prinzip der parmenidischen Doktrin unverträglich."

44 B 8 , 53. Se trata de formas "elementales". Cf. Kranz, Wortindex, p. 287. Sobre el verdadero sentido de estas formas, véase Arist., Metaph., A, 5, 986b 31. Cf. Arist., phys., A, 5, 188a 19; de gen. et corr., A, 3, 318b 13; B, 3, 330b 13, y B, 9, 336a 3. 
primer gran error, como nos dice Parménides, del que derivan todos los demás. En lugar de atenerse al único principio conducente, a tò ơv, sientan una duplicidad de principios, a partir de la cual se efectúa todo ordenamiento engañoso. Tal duplicidad se presenta, evidentemente, como algo necesario para la constitución de ese orden o mundo de la opinión. Una sola forma elemental no bastaría para ello. ${ }^{45}$ La esencia de la opinión es el dualismo de donde sólo puede derivar el hecho de darse "atributos" ( $\sigma \eta \mu \alpha \tau \alpha$ ) completamente diferentes los unos de los otros, pues en un monismo como el que proclama Parménides no hay sitio para una oposición entre las características del ente. ${ }^{46}$ Ellas están, por así decirlo, unificadas, en tanto que son sus características, y forman una unidad con él.

Dichos principios o formas son la Luz y, la Noche. ${ }^{47}$ Sus nombres mismos aluden ya a esa condición ineludible para todo dualismo: la aceptación de las oposiciones. Esto es importante, ciertamente. Pero no menos importante y revelador es la relación de tales expresiones con el simbolismo entero del Proemio. En esta introducción pretendidamente piadosa se nos habla metafóricamente del hallazgo de una nueva y única verdad y de un camino aún no seguido por nadie para acceder a ella. Aquí desempeñarán un importante papel la Luz y la Noche, vistas bajo diversos aspectos. Como se recordará, Parménides es conducido hacia la Luz ( (B 1, 9-10). Las puertas que franquea son las que, en una dirección, llevan al camino de la Noche, y en otra al camino del Día. ${ }^{48}$ En su término lo espera la Diosa, o lo que es lo mismo, la verdad revelada; figura que para el filósofo representará lo mismo que las Musas para el poeta. Todo esto nos habla de un simbolismo consciente y querido, en que el elemento lumínico del Proemio alude claramente al ente y a su entrañada racionalidad. Los caminos del Día y de la Noche no vienen a ser más que las vías del ente y del no ente, con otro

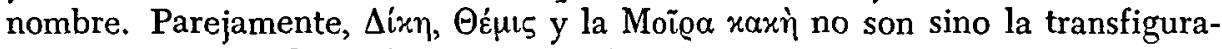
ción de la necesidad inherente, sea al ente mismo, en un caso, sea al vocĩv

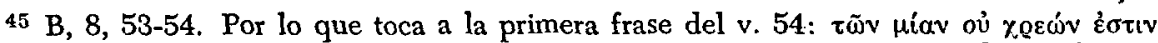
(scil. ỏvouábetv), obsérvese que "dar nombre" implica aquí aceptar como real aquello que se nombra. En este sentido, Parménides nos dice que no es necesario aceptar como real una de las formas que se oponen entre sí, o lo que es lo mismo, que no es necesario -dado que ellas se requieren mutuamente de modo necesario, a causa de su esencial oposiciónaceptar el dualismo como algo real y verdadero. Cf. Diels, op. cit., p. 93. En relación a

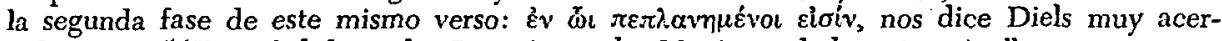
tadamente: "Hierin' d. $h$. in der Bestreitung des Monismus haben sie geirrt".

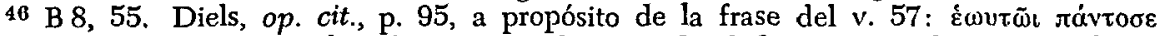

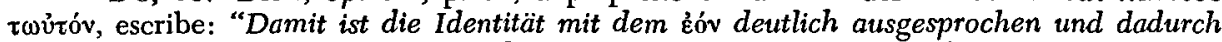
der Widersinn des Dualismus zugleich mit dem Sinne des Monismus kurz dem Wissenden dargelegt."

47 B 9, I,

48 Es claro que las puertas de los caminos de la Noche y del Día se abren para dar paso en una dirección o en otra y, en este sentido, dividen el sendero entero; el cual, por un lado, recibe el nombre de sendero de la Noche y, por otro, el de sendero del Día. Cf. P. Albertelli, op. cit., p. 123, n. 14. 
en otro, o la personificación de la arbitrariedad y falacia propia de las opiniones de los mortales. ${ }^{49}$ Todos estos elementos figurativos, por otra parte, han sido tomados, evidentemente, de la tradición y particularmente, como lo ha mostrado Diels, de Hesíodo. ${ }^{\overline{0} 0}$

Algo semejante ocurre con la mayor parte de los elementos concretos que figuran en la segunda parte del Poema. También éstos debieron haber sido tomados de las ideas corrientes en esa época. Identificar el origen de unos y otros no cae en el ámbito de nuestro trabajo. Lo realmente importante es el uso que Parménides hace de ellos y la intención doctrinal que lo guía. Porque, de hecho, todos estos elementos no embarazan o complican lo positivo de la doctrina. El eleata nunca abandona en lo más mínimo los límites de ella. El hecho de que el ente reciba el nombre de Luz, y el no ente el nombre de Noche, se debe al peculiar enmascaramiento de la verdad en que consiste la opinión. Esta es incapaz de suyo de atenerse al ente únicamente. Para dar cabida a lo variable y múltiple precisa un segundo factor que en el fondo no puede ser sino el no ente; pero esta contradicción, inherente en lo mismo que propone, no se hace evidente debido, justamente, a que tanto el uno como el otro son nominados en una forma tal que hace imposible ver su mutua exclusión y la única vía posible de llegar a la verdad. Tomadas, por lo contrario, Luz y Noche como los principios de que deriva todo el orden de la opinión, ambas se requieren mutuamente al par que se oponen por sus mismos caracteres; una es el complemento de la otra, y viceversa. ${ }^{51}$ Igualmente, todas las oposiciones particulares que de aquí resultan -oposiciones de nombres, en realidad, originadas por esa cualidad o potencia de ellos,$-^{52}$ se requerirán mutuamente. No podría concebirse nada más alejado de la verdad y que a la vez entrañara más riesgo para ella. Pero, conociendo el núcleo originario de semejante entre-

49 Cf. Jaeger, Paideia, I, ed. cit., págs. 196-197. La singular Moīo $\alpha$ del v. 26, en virtud del calificativo que la acompaña, alude visiblemente a la falta de razón y de derecho que es característica de la Vía de la Opinión. En contra del punto de vista de Diels, op. cit., p. 54, creemos que las Doncellas Solares se identifican con $\Delta i x \eta$ y $\Theta \dot{\varepsilon} \mu \iota \varsigma$ del v. 28. En consecuencia, la $\Delta i x \eta$ del v. 14 es distinta de ésta. Parécenos que la primera, la $\Delta i ́ x \eta$

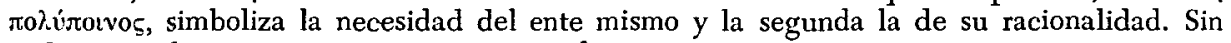
embargo, todo esto es meramente conjetural.

50 Diels, op. cit., págs. 10,47, 48, 50,52. Para otros antecedentes todavía es provechoso consultar la misma obra, págs. 11 sigs., así como el comentario a los versos del Proemio, págs. 46-63.

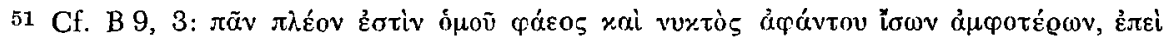

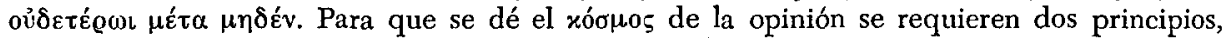
puesto que no podría darse con ninguno de ellos aisladamente. El parecer de Patin acerca de que aquí se plantea la crítica fundamental de Parménides en contra de la Vía de la Opinión haciéndonos patente el absurdo de dos principios en el mismo plano metafísico, uno de los cuales sería el ente y otro el no ente, es demasiado alambicada, y, por otra parte, ello ya ha sido suficientemente mostrado. Véase P. Albertelli, op. cit., p. 151, n. 4.

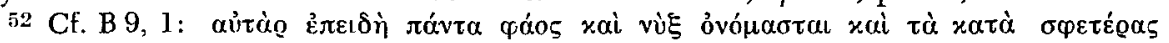

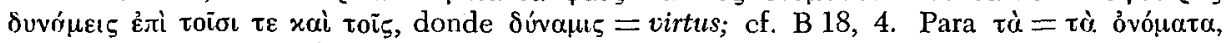
cf. Diels, op. cit., p. 101. 
lazamiento totalmente aparente, se desvanece todo peligro. Ninguna opinión de los mortales podrá ya imponérsenos jamás. ${ }^{53}$

Todo un mundo de cambio, donde las cosas más variadas se mudan en otras, se generan o perecen, donde el hombre mismo se desenvuelve, nace y muere, al amparo todo de ciertos dioses, se nos patentiza como una mera colección de nombres que no hincan su raíz en nada real. El error consiste en no caer en la cuenta de que ello es así. Pero, como hemos visto, el mismo error, para Parménides, obedece a una particular causalidad y a una ley de desarrollo que parte de la Luz y de la Noche, tomadas como ingredientes primarios, y concluye en un deus ex machina, "la diosa que todo lo gobierna", causa última de toda unión y separación de los componentes del cosmos. ${ }^{54}$ Las concepciones en general del espíritu griego de este tiempo caen por su base. Son mera palabrería. La verdadera expresión, fundada en el logos, no nos habla de muchos, sino de uno, no de un nacer y perecer, sino del ente únicamente. La primitiva concepción de todos los pueblos acerca de que la efectiva realidad de las cosas es aprehendida en los nombres propios de ellas, deja de tener influencia en el pensamiento de Parménides. ${ }^{55}$ Sólo el voвĩv puede captar la realidad y dar un fundamento a su expresión. ${ }^{56}$ Filosofía y mito responden a las mismas motivaciones. Su explicitación, tal como lo ha hecho el eleata, nos muestra el verdadero valor que les corresponde. Pareja tarea no había sido llevada a efecto hasta entonces con tan singular hondura y penetración. La causa debemos buscarla en la misma doctrina de Parménides. El descubrimiento del ente y de los caracteres que le son propios parece de por sí tan evidente, que se hacía necesario explicar el porqué de una ceguera frente a ellos. La fuerza de la evidencia debe haber sido suplantada, pues, por la fuerza derivada de las múltiples experiencias y de las $\delta o ́ \xi \alpha$.

Este hecho es el que ha posibilitado la proliferación de las concepciones de los mortales. Pues sólo a partir de un fundamento absurdo, velado, parecen haberse generado las cosas y llegado a su estado actual, para alcanzar finalmente su término. Pero, de hecho, eso sólo ha ocurrido y puede ocurrir en un reino fantasmagórico de meras palabras. ${ }^{57}$ La verdadera realidad es muy otra

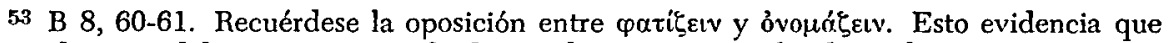
la segunda parte del Poema es vista desde un plano superior a fin de explicar su mecanismo. Para la opinión contraria de Reinhardt, véase P. Albertelli, op. cit., p. 150, n. 54.

54 B $12,3$.

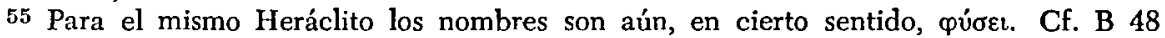

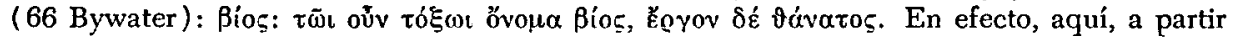
de la semejanza linguística entre $\beta$ ıós y Bíos, Heráclito hace patente la lucha y contradicción perenne de las cosas mismas. Algo semejante podríamos encontrar también en B 32 ( 65 , Bywater) y en B 67 (36, Bywater). Por eso no parece acertado el punto de vista de Gigon, op. cit., p. 258: "Der Name hatte ja auch bei Heraklit eine bestimmte verwandte Funktion."

56 De tal modo, no vemos cómo Diels, op. cit., p. 85, pueda pensar lo contrario: "Parmenides folgt also sichtlich der uralten Vorstellung aller Völker, dass ein Ding erst wahre Realität erhält durch die Fassung im Wort."

57 Cf. B 19. 
y surge por contraste con ésta. En efecto, toda la teoría sobre el ente se sitúa sobre un segundo plano constituído por las efectivas opiniones que formaban el ambiente espiritual y conceptual del tiempo de Parménides. Como es de esperarse, la concepción eleática del ente se halla condicionada en gran medida por las limitaciones de esa circunstancia. Por otra parte, en la pugna que se establece entre la nueva concepción y las otras, resultan todas ellas aclaradas. Por lo menos, así sucede ante los ojos de Parménides; pues es entonces, ciertamente, cuando se nos demostrará que el aceptar el cambio, la diversidad, la generación y la muerte, implica ineludiblemente la aceptación del no ente. Es decir, se aclara el erróneo punto de partida de la opinión, tanto como la razón última del dualismo esencial a toda $\delta o ́ \xi \alpha$, que vemos ejemplificado con el doble establecimiento de la Luz y de la Noche. El no ente, a su vez, nos aparecerá como el requisito último de todo aquello que de sí excluye el ente: generarse y perecer, multiplicidad y cambio en general. Queda

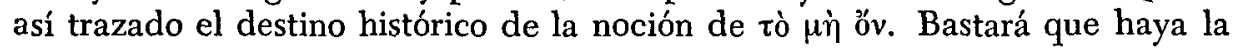
pretensión, por parte de algunos de estos específicos factores excluídos, de entrar en el ámbito de la realidad, para que de inmediato se acuda a tal noción como medio de salvación y explicación de ellos. El gran ejemplo es el atomismo. Pero huellas de ese planteamiento las podemos encontrar en toda la historia de la filosofía. Su influencia ha sido perdurable e incitadora.

4. A lo largo del camino que conduce a la verdad, semejantes a los postes indicadores de la ruta, encontramos los atributos del ente, las señales ( $\sigma \dot{\eta} \mu \alpha \tau \alpha$ ) que deslindan la realidad existente del no ente. Lo que es no se ha generado y no puede perecer. Estas son las dos primeras características que Parménides adjudica al ente. Su comprensión es aparentemente-muy sencilla y accesible. Pero eso es justamente lo que a la larga ha tornado difícil y laboriosa la captación auténtica del verdadero sentido de las palabras del eleata. En efecto, su sentido original ha sido substituído las más de las veces por otro sentido derivado del que para los intérpretes era cotidiano y corriente. Esto, sin embargo, empaña la captación del pensamiento de Parménides y plantea una serie de dificultades que no tienen razón de ser. Generarse y perecer, en el Poema, no quieren decir algo semejante a lo que es sólito entender hoy al oír o leer estas palabras, o incluso a lo que pocos siglos después de Parménides iban ellas a significar; sino algo muy simple, tan extremadamente simple como pudo ser su conceptuación en tal época. Es indudable, por otra parte, que el mismo planteamiento de la argumentación en el fragmento octavo de la obra posibilita ciertos malentendidos. Hoy tendemos casi siempre a no ver en esto más que un problema puramente metafísico, establecido y resuelto en términos exclusivamente metafísicos. Pero en Parménides no es así, ni pudo serlo. Si nos mantenemos dentro de la circunstancia histórica en que el Poema hubo de plasmarse y tenemos clara conciencia de ella, no será difícil llegar a comprender que nos las habemos con una refutación de las tendencias genera- 
les, peculiares de toda esa circunstancia, la cual se ofrece en el mismo plano de entendimiento que ellas.

Recorriendo la historia de la cultura griega anterior a Parménides, será fácil entrever lo que de semejante tienen todas las interpretaciones y matices del generarse y el perecer, cosmológicamente hablando. Para un griego de ese tiempo la cosa no ofrece mayores dificultades. Hay generación cuando surge algo diferente, distinto, de aquello que ya era y a partir de lo cual se ha dado. El concepto es, como se ve, sumamente ingenuo todavía. En esencia, la generación implica un cambio de algo que se presenta de tal modo a otra cosa que se presenta de otro. Dada la pobreza conceptual no se puede ir más allá. La generación se ofrece, pues, como un hecho acompañado de tales características y nada más. Sea la fuente expresa, de la cual todo deriva, el Caos. de Hesíodo, o sean el Tártaro y la Noche de Museo, o el Caos, Erebos y Nyx de Acusilao, o bien el agua de Tales o el ápeiron de Anaximandro, etc., en todos estos casos ocurre lo mismo. Pues aunque en rigor Hesíodo no nos dice que e! Caos fuera lo primero de todo $y$, por ende, algo ingenerado, sino, antes bien, afirma que "primero se generó el Caos" y luego todo lo demás, es evidente que si le hubiera sido posible pensar en un principio más radical y filosófico, éste no podría ser el mismo Caos, sino algo bien diferente. ${ }^{58}$ Pero en Anaximandro encontramos un pleno y consciente uso de este carácter esencial. El principio de las cosas o entes es lo que él denomina tò ör $\varepsilon\llcorner\varrho o v$. Estas han llegado a ser lo que son, algo diferente o distinto del ápeiron, a partir de esa ủo $\chi$. Parejamente, su destrucción o perecer equivale a la pérdida de su distinción en tanto que cosas, a un cambio más y a un regreso a su fuente originaria. ${ }^{50}$

De acuerdo con este esquema tan simple y omnicomprensivo, Parménides va a mostrarnos que lo que es no puede generarse ni perecer. En efecto, ¿qué

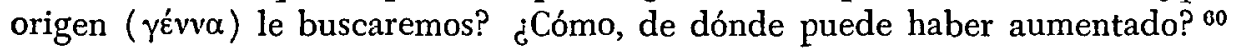
En estas preguntas se nos revela el carácter aún muy primitivo de las consideraciones corrientes sobre la generación; ${ }^{61}$ pero también se plantea. con la primera de ellas una cuestión ineludible, que no puede tener más que una sola respuesta. Pues, si suponemos que el ente se ha generado, éste sólo puede tener su origen en algo distinto de él, en algo otro que él, y no en sí mismo, lo que sería absurdo. Este algo distinto, supuesto que estamos hablando de lo que es, no puede ser, en consecuencia, sino lo que no es, el no ente. Una segunda respuesta no tendría sentido. Lo que es no puede haberse generado de lo que es, de sí mismo, a no ser que pretendiéramos que el segundo ente

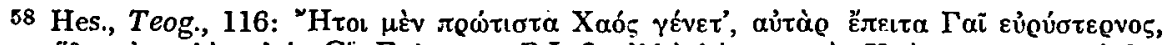

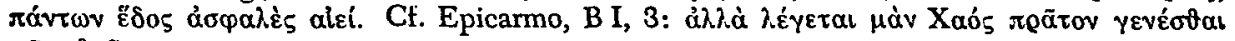
$\tau \bar{\omega} \nu \vartheta \varepsilon \tilde{\omega} v$.

59 Anaximandro, B I (Simplicio, phys., 24, 13).

60 Cf. B 8, 6.

61 Cf. Cornford, op. cit., p. 36. 
tiene características que lo hacen diferente del primero. Pero, para Parménides, una cosa así es absolutamente impensable. Un segundo ente, aun con un solo atributo distinto, ya no sería ente. Por esto, resultan ociosas todas las enmiendas propuestas del texto del Poema, para incluir en él la refutación de que lo que es pueda generarse de lo que es. ${ }^{62}$ En realidad, no hay ninguna razón para hacerlo, ${ }^{13}$ ni mucho menos para afirmar que, a pesar de no estar ello expresamente formulado, es evidente de suyo. ${ }^{64}$ Sólo el tomar demasiado en serio los testimonios de Aristóteles y Simplicio ha hecho posible semejantes interpretaciones. $^{65}$ Pero a Parménides lo que le preocupa únicamente es el problema del nacer, que es siempre para él un nacer del no ente, en concordancia con los rasgos esenciales de la generación.

Por otra parte, esto no significa que el pensamiento filosófico preparmenídeo haya aceptado una generación a partir de lo que no es. Parménides no está refutando una concepción de tal índole, sino, por lo contrario, tratando de establecer una teoría verdadera, para la cual la admisión de la generación y la muerte implica necesariamente algo tan falto de sentido como es el recurrir al no ente. Que, de hecho, no se haya dado algo parecido en las distintas doctrinas que antecedieron a la del eleata, no quiere decir que, para el punto de vista adoptado en la vía de la verdad, ello no sea así. ${ }^{60}$ Tal es el punto crítico. Lo que existe no puede derivar, nacer, de lo que existe, pues lo que existe es siempre igual a lo que existe; no se puede distinguir un ente generante $y$ un ente generado $y$, por ende, no es posible el paso generador del uno al otro. Luego, si se habla de generación o de perecer, es porque subrepticiamente se ha colocado ahí lo que no existe, enmascarado por alguna palabra. Como se ve, la concepción de la generación como un surgir de lo que no es constituye una concepción específicamente parmenídea, tomada, claro está, dentro de su intención refutativa. Incluso, puede decirse que es

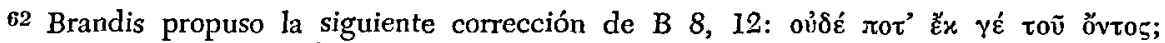

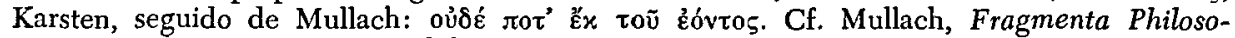
phorum Graecorum, Poeseos Philosophicae, F. Didot, Paris, 1860; p. 121, n. al v. 68. A

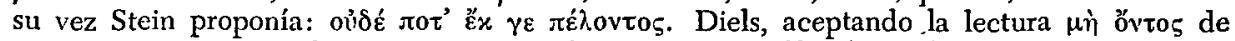

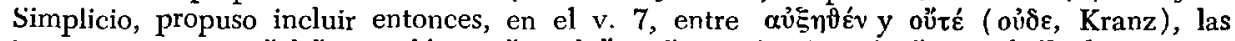

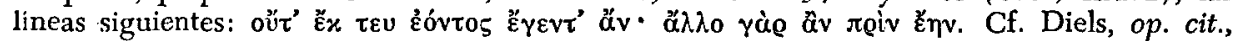
p. 77. Reinhardt y Gigon, op. cit., p. 262, en nuestros días, se han adherido a la corrección de Karsten.

63 Las razones que esgrimía Diels, op. cit., págs.: 76-77, para incluir la refutación expresa de un generarse de lo que es a partir de lo que es, no son convincentes: "Aber der Text ist dadurch noch nicht in Ordnung. Es bleibt der doppelte Anstoss: 1) Die Widerleg-

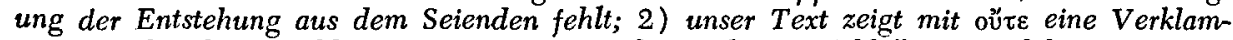
merung, der der Anschluss sei es vorwärts oder rïckwärts fehlt." Más adelante veremos que el texto tampoco presenta esa segunda dificultad de que nos habla Diels.

64 Véase la nota respectiva de Kranz, en contra de la interpretación de Diels, en Die Fr. der Vors.: "aber wahrscheinlich setzen V. 6/7 Entstehen und Wachstum aus dem Seienden als selbstierständlich an".

${ }^{6 \bar{s}}$ Arist., phys., A, 8, 191a 27. Simpl., phys., 34.

${ }^{66}$ La justificación de los argumentos ya citados de Diels, apoyada en tal hecho histórico, es, pues, inconducente. Véase Diels, op. cit., p. 77. 
la primera mención que se hace en la historia del pensamiento universal de un nacimiento ex nihilo. Pues aun los mismos hebreos están muy lejos de concebir la idea del no ente de esta manera tan radical, ${ }^{67}$ debido, en gran parte, a lo que para ellos representaba el ser (hajya): la unidad de ser, llegar a ser y obrar. ${ }^{68}$

De tal modo, supuesto que sólo es posible un generarse a partir de tò $\mu \grave{\eta}$ őv, Parménides pasará a mostrarnos palpablemente la inconsecuencia que en ello se encierra. Una cosa así no puede ni siquiera pensarse o expresarse, a causa precisamente de la intromisión del no ente. ${ }^{69}$ Lo que no es, es impensable, y la expresión, para ser verdadera expresión, debe estar fundada en el pensar mismo. De otro modo, se trata simplemente de un lenguaje convencional y aparente, como es el llamar Noche al no ente, o de un lenguaje sin base en realidad y apariencia algunas, como es la misma palabra "no ente". Parménides no nos dice que el no ente no sea "nombrable", sino que no es "expresable" ( $q \alpha$ tóv), lo cual es muy diferente. ${ }^{\text {To }}$ Todo logos está negado a lo que no es. Esta demostración es, tocante al meollo mismo de la doctrina parmenídea, la fundamental. Y vale igualmente en contra de todo supuesto perecer por parte de lo que es. Pues la generación implica tanto el no ente como lo implica el perecer. Por esto no encontramos en Parménides ninguna refutación especial de este último. Al excluir el principio se excluye necesa-

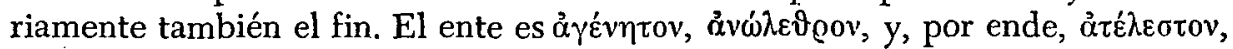
sin fin en el tiempo. ${ }^{71}$ La respuesta a la pregunta acerca de la posibilidad de Ja destrucción se muestra tan absurda como la respuesta a la pregunta similar referente a la generación. El carácter mismo del ente excluye, obligadamente y en justicia, tales factores. ${ }^{72}$

Esta argumentación se complica todavía con una segunda. Admitamos, como concesión última a las opiniones de los mortales, que el ente nazca de la nada; pues bien, en semejante caso, ¿qué necesidad lo ha llevado a nacer antes o después? ${ }^{73}$ En realidad, si admitimos la generación, da lo mismo que

67 Véase Thorleif Boman, Das hebräische Denken im Vergleich mit dem Griechischen, Vandenhoeck und Ruprecht, Göttingen, 1954, p. 43: "Das wahrhaft Seiende ist für den Hebraër das Wort, dabar, das alle hebräischen Realitäten umfasst: Wort, Tat, Sache. Das Nicht-Seiende, das Nichts, heisst demgemäss Nich-Wort, lo dabar. Das Nicht-Seiende, die Nichtigkeit, hat aber auch für den Hebräer eine gewisse Existenz, die im praktischen Leben sehr greifbar und unangenehm ist", y p. 45: “. . . ihre Existenz ist diejenige des Scheins, die auf Erden und im Menschleben doch eine verhängnisvolle und böse Rolle spielen kann". Cf. F. M. Cleve, The philosophy of Anaxagoras, Columbia University, 1949, págs. 77-81.

es Th. Boman, op. cit., p. 44.

69 B $8,7$.

70 B 8,8 .

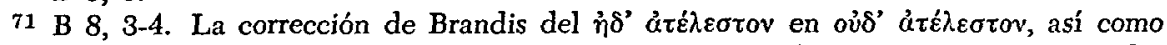
la traducción de Patin: non perfectibile, se basan en una inadmisible confusión entre los límites "espaciales" y los temporales, derivada de B 8, 32-42.

72 B 8, 13. 
el ente sea en tal momento o en otro, ahora o después. Ninguna necesidad le marca el instante preciso de su inicio. Así como ahora es, a causa de haberse ya generado con anterioridad, puede muy bien no ser, estar por generarse. Si

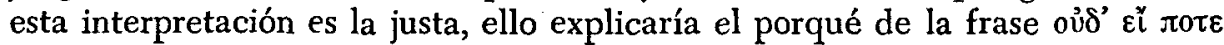

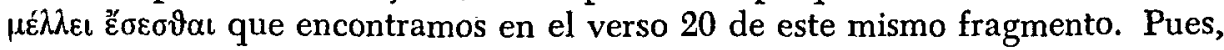
en efecto, si el ente puede llegar a ser en el futuro es porque ahora no es, no existe; de otro modo, ¿cómo podría ocurrir algo semejante? 74 Aceptando que la pensabilidad $y$, por ende, la expresabilidad no constituyan la pauta última que permite distinguir la realidad de su contrario, aceptando la generación a pesar de todo, vamos a dar al absurdo total. No hay forma alguna de mantener la génesis ni la destrucción; pues, como es fácil verlo, toda esta nueva argumentación vale igualmente tanto frente a la primera como a la segunda. ${ }^{75}$ Tanto la una como la otra carecen de toda justificación. La generación, aparentando entregarnos el ente, lo anula de hecho. La nada que postula no sólo puede presentarse en el pasado, sino que también ahora. El ente no sólo puede perecer, sino que también puede ya haber perecido. La imposibilidad

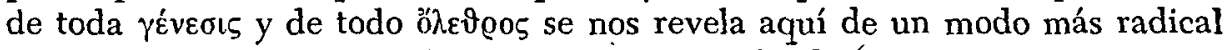
todavía y en plena concordancia con el juicio fundamental de la vía del no

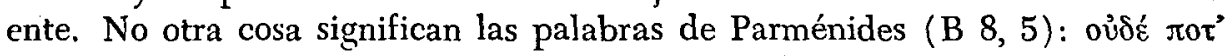

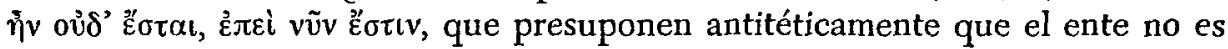
ahora, porque fué o será, es decir, porque yà pereció o está por generarse. ${ }^{70}$

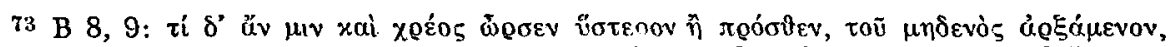

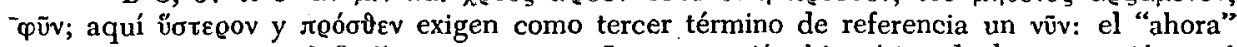
que encontramos en B 8,5 precisamente. La aceptación hipotética de la generación está

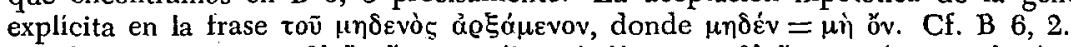

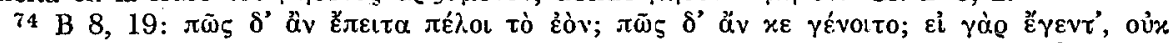

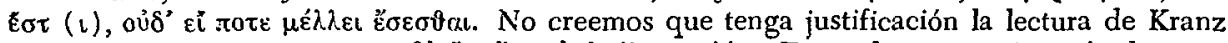

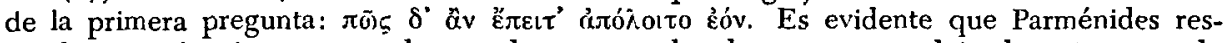
ponde en orden inverso, en el segundo verso, a las dos preguntas, dejando entrever todo el error que entraña tanto una generación ya efectuada, como una por efectuarse. Respecto a la primera, el argumento básico en su contra se desprende de la inmediata alusión a la impensabilidad e inexpresabilidad de lo que no es, en B 8, 7-8. El ente, pues, no se genera $y$, por consiguiente, si se genera no es. En cuanto a la segunda, es claro que el ente no puede ser ahora si está por generarse o por llegar a ser en el futuro; lo cual es absurdo. Con estos versos y el siguiente concluye la demostración de los dos primeros atributos del ente. Véase n. 75 .

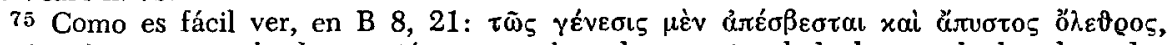
tanto la génesis como la destrucción son rechazadas en virtud de los resultados de todos los argumentos anteriores, al igual que en B 8, 13-15.

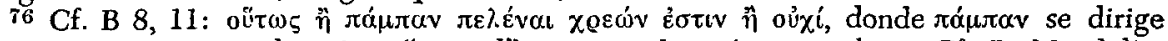
evidentemente contra todo existir "parcial", antes o después y no ahora. Cf. R. Mondolto, El infinito en el pensamiento de la antigiiedad clásica, Imán, Buenos Aires, 1952; p. 101. En Anaxágoras, B 12, 10, encontramos una expresión muy parecida, sólo que en sentido

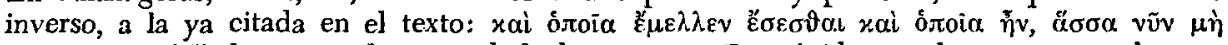

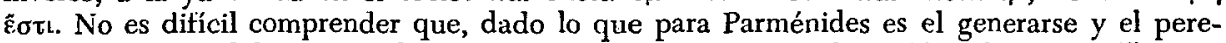
cer (un cambio del no ente al ente, y viceversa), decir que el ente "fué" o "existió" equivale a decir que ha pasado de ente a no ente, que ya no es o que ha perecido. De modo similar debe entenderse el "será" o "existirá", el estar por generarse. 
La impensabilidad e inexpresabilidad de una teoría que acepte el generarse y el perecer constituyen la principal razón en su contra. Pero, admitidas esas condiciones ex hypothesi, los resultados son, como se ve, aún más desastrosos, dada la esencial falta de localización temporal de toda génesis y destrucción: el ente se aniquila en el ahora de su presencia y su presente. Por eso, de

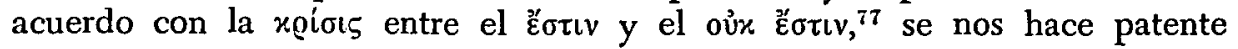
de una vez por todas que el ente no sólo es ahora, como ya lo sabíamos desde el momento mismo en que hubieron de plantearse las dos vías, sino que nunca ha podido o podrá no ser. No ha perecido ni va a generarse, así como tampoco se generó ni puede destruirse. Las consecuencias de esto son, partamos o no de una aceptación hipotética que se revela absurda, que lo que ahora existe no tiene ni puede tener principio ni cese algunos. ${ }^{i 8}$

De aquí a afirmar que el ente es, ha sido y será siempre ya no hay más que un paso. No obstante, Parménides no ha llegado expresamente a semejante conclusión, aunque de hecho ella está ya en germen dentro de sus propias palabras; pues el ente excluye, ciertamente, todo pasado o futuro, pero sólo en el caso de que impliquen su inexistencia. Además, la carencia, por

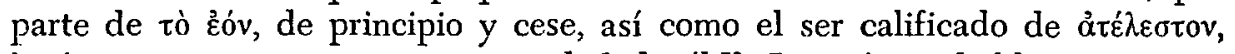
harían pensar en una cierta eternidad de él. ${ }^{79}$ Lo más probable es que sea así. Sin embargo, sólo hasta Meliso encontramos, dentro del eleatismo, la formulación cabal de una tal eternidad, la cual deriva justamente de la falta, característica en lo que es, de todo principio o fin. ${ }^{30}$ Que Meliso haya podido encontrar la expresión ya hecha en Heráclito, no es dudoso, pero es más lícito suponer que no hizo otra cosa sino desarrollar los motivos larvados en el pensamiento de Parménides, extrayéndole hasta sus últimas consecuencias. ${ }^{81}$ Por todo esto, ateniéndonos rigurosamente a lo que el mismo Poema nos dice, no podemos ir más allá de esta comprobación sumaria, sin aceptar, claro está, la pretendida concepción de la extratemporalidad que ahí se dice estar patentizada, ni mucho menos la zeitliche Allgegenwart de que nos hablaba Bauch. ${ }^{82}$

77 B $8,15$.

78 B 8, 27. El texto confirma la interpretación de ảน en el tiempo.

79 La peculiar concepción de Mondolfo, op. cit., p. 101, de la infinitud del ente, he-

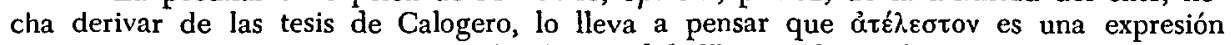
equivoca entre la temporalidad y la "espacialidad", con lo cual no podemos estar de acuerdo.

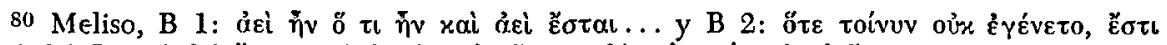

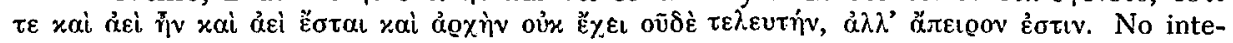
resa por lo pronto discutir aquí si ěkeıoov tiene un sentido espacial o temporal. De todos modos, lo que primero se deduce de esa carencia de principio o fin es la infinitud temporal. Si ésta se hace después coincidir con la espacial es algo que ya veremos en el capítulo siguiente.

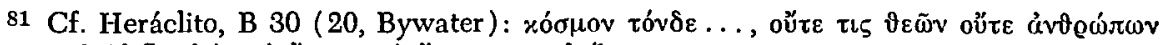

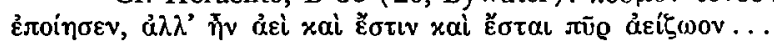

82 Bauch, Suzstanzproblem, p. 44 (citado por Albertelli, op. cit., p. 143, n. 11). El 
Todas estas interpretaciones, corrientes ya desde la antigüedad, ${ }^{83}$ han tendido a ver en la cuestión, bajo el influjo de las sugestiones del Timeo platónico, más sutilezas de las que en realidad hay. La singular "eternidad" (mejor sería decir: extratemporalidad o intemporalidad) que Platón adscribe a la oủoí ha venido a constituirse, de esta manera, en el modelo que permitiría explicar la eternidad del ente parmenídeo.

En efecto, para Platón, el "fué" y el "será" son formas del tiempo, formas engendradas a imitación de la "eternidad", $\$ 4$ que no pueden ser aplicadas de ningún modo a lo "eterno". Cuando decimos que la oủoía es, fué y será, no aplicamos en realidad esos términos correctamente; pues "fué" y "será" son expresiones que sólo convienen a lo mudadizo y cambiante. ${ }^{8 \check{a}}$ La oủoía en

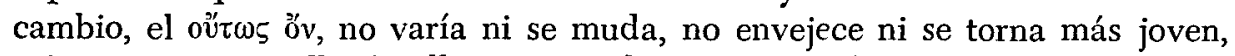
así como tampoco llegó o llega a ser ahora, o en el futuro. ${ }^{86}$ De este modo, Platón puede concluir diciéndonos que la única expresión aplicable al ente verdaderamente ente es el ह̌otıv y nada más. ${ }^{87}$ Semejante teoría ¿ayudaría a explicar la parmenídea? El problema doctrinal que se plantea es grave. Parménides ¿habría concebido la eternidad como un puro presente, inmune a toda diferenciación temporal de pasado o futuro? El verso 5 del fragmento octavo podría interpretarse en esta forma. ${ }^{88}$ Pero ¿no es más lícito pensar que si se nos dice que el ente no fué ni será, puesto que es ahora, se nos dice que no ha perecido ni se generará, porque, ya siendo, es inconcebible que no sea, que ya no exista o esté por existir? Lo cual vendría a mostrar únicamente el carácter paradójico de toda génesis y corrupción, para en seguida deducir de ese hecho el verdadero carácter del ente y sus atributos subsiguientes más importantes. ${ }^{89}$ Por otra parte, parécenos que la afirmación eleática, acerca de que lo que es no tiene principio ni cese, presupone un concepto de la eternidad muy distinto del platónico. El mismo Calogero, uno de los principales defensores de la tesis de la extratemporalidad, ha tenido que reconocer que, en

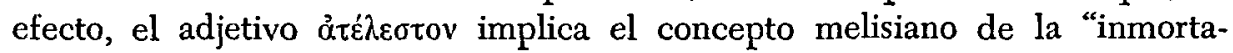

término es muy complejo para designar lo que haya podido ser el concepto de eternidad en Parménides.

83 Véase, por ejemplo, Ammonio, de interpr., 136, 21.

84 Plat., Timeo, 37e 4.

85 Plat., Timeo, 37e 5 y 37e 7-38a 2.

86 Plat., Timeo, 38 a 2.

87 Plat., Timeo, $37 \mathrm{e} 6$.

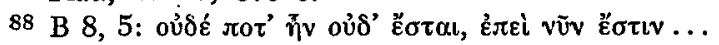

89 Carácter paradójico, por cuanto la generación y el perecer no sólo admiten el no ente en el pasado o en el futuro, sino, lo que es peor aún, también en el ahora, en el presente, como se ve desde el momento mismo en que, colocados en el terreno propio de la opinión, se admiten hipotéticamente. Su refutación consistirá, por consiguiente, en mostrar que lo que es no sólo es ahora, sino también en el pasado o en el futuro, en substituir el no ente, en todo y cualquier momento del tiempo, por lo que es. 
lidad". ${ }^{90}$ En rigor, semejantes términos no pueden entenderse más que a partir de una extensión temporal, suma de presente, pasado y futuro.

Pero quizá el factor más decisivo en esta cuestión sea el factor histórico. No hay ninguna razón para suponer que Meliso no haya dado plena expresión a los supuestos tácitos que se encuentran en el Poema de su maestro. La concepción de la extratemporalidad de la verdadera realidad, en oposición a la temporalidad propia de las cosas cambiantes, es demasiado elaborada incluso para los tiempos de Meliso. Ligar estrictamente el tiempo con el movimiento, para deducir de ahí la incontaminación con él de lo que, por naturaleza, es completamente ajeno a todo cambio, es obra exclusiva de Platón. La confusión entre esta teoría y la de Parménides no ha derivado más que de la confusión, que tan frecuentemente encontramos en los doxógrafos de la antigüedad, entre

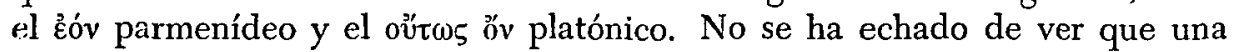
conceptuación del tiempo como la platónica requiere ineludiblemente la aceptación de dos órdenes diversos de existencia, a los que vendrían a corresponder el tiempo, por un lado, y la negación de él, por el otro. Si la segunda parte del Poema pudiera interpretarse como la admisión de ese mundo cambiante y temporal, entonces tal vez no estuvieran muy alejados de la realidad los sostenedores de la tesis de la extratemporalidad en Parménides. Pero ello no es así. Más bien, eso constituye otra prueba más de la anacrónica "platonización" del eleata: uno de los grandes mitos de que se encuentra plagada la historia de las interpretaciones antiguas de la filosofía griega y que aún hoy sigue influyendo considerablemente. En consecuencia, para atenernos a los hechos mismos, debemos dejar establecido que lo más seguro es que, para Parménides, el no ente no puede darse en el pasado ni en el futuro y, mucho menos, en el presente, esto es, que el ente ha sido, es y será eternamente, tal como Meliso vendrá a afirmar con toda claridad.

Aquella primera pregunta por el origen de lo que es queda contestada en esta forma negativa. No hay una génesis total del ente ni, al par, una destrucción de él. Pero quedaría todavía por responder otra pregunta que, en rigor, es bien distinta de la primera. Recuérdese, en efecto, que inmediata-

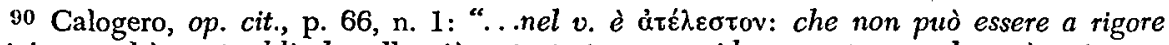
spaziale, perchè contraddirebe alla più nota tesis parmenidea, ma temporale può poi esser scltanto in quanto il motivo, che può dirsi melissiano, della "immortalita" vi prevale su quello, che immediatamente dopo si afferma, della pura presenza". Ya antes Calogero nos había dicho (p. 61): "In Parmenide l'eternita è superiorità al tempo, presente senza passato e senza futuro." Sin embargo, recuérdese el curioso texto de B 8, 36:

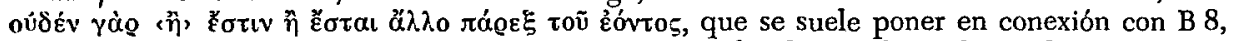
12-13, atendiendo quizá demasiado y sin razón a su similitud formal. Traduciendo, en cambio, como es lo más lógico hacer: Nada distinto, pues, es o será excepto (xáoєx c. gen.) el ente, no es difícil ver que tò çón no excluye el "será", el futuro, sino antes bien lo exige como conclusión de su carácter de imperecedero, de su existir total, lo cual se torna más factible

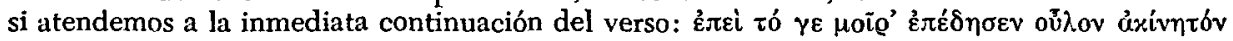

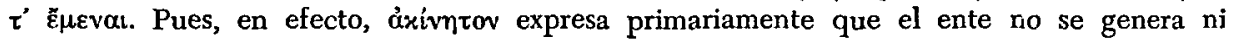
perece. 


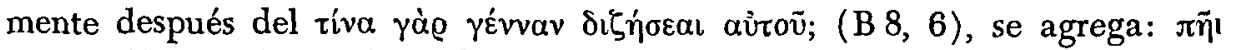

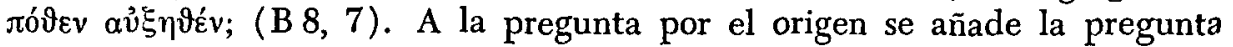
por. el aumento. ¿Puede haber aumentado el ente? Las respuestas a ambas cuestiones, puestas en relación mediante el oủó́ con que se inician, una, como ya vimos, en B 8,7 y la otra en B 8, 12, parten de una misma pretendida posibilidad para pasar en seguida a mostrar su falacia. ${ }^{91}$ Ciertamente, ni del no ente puede decirse o pensar que se haya originado el ente, ni del no ente permitirá nunca la evidencia que se genere algo $(\tau \iota)$ junto a él ( $\pi \alpha Q^{\prime}$ av̉ró), a su lado. $^{92}$ Esto quiere decir que el ente no puede aumentar en número, que nada puede venir a agregársele, a hacerle perder su carácter de ser todo a la vez ( ente es uno, hubo de verlo ya el mismo Aristóteles y, a continuación de él, Teotrasto y parte de la doxografía basada en sus $\Phi v \sigma \iota x \tilde{\omega} v \delta \delta^{\prime} \alpha_{\alpha .}{ }^{94}$ Es curioso comprobar cómo raras veces se le ha dado su verdadero sentido a esta prueba, llegándose incluso a afirmar que Parménides no da ninguna demostración de la unidad de lo que es y que Teofrasto viene a suplir esta carencia. ${ }^{95}$ Cierto es que, para completarse, ha de ponerse en conexión con el argumento en contra de la divisibilidad del ente, cosa de la que no se percataron Aristóteles y Teofrasto; ${ }^{96}$ pero, así integrada, no deja lugar a dudas tocante a su alcance.

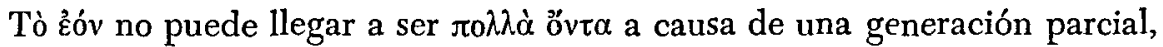
así como tampoco a causa de una división que viniera a multiplicarlo. El ente, puesto que es todo igual, tiene que ser indivisible. Todo está lleno de lo que es; no hay algo más en algún lado ni algo menos, pues esto presupondría de inmediato el aceptar el no ente. ${ }^{97}$ Sólo a partir del efectivo darse de esta noción podría lo que es dividirse, disgregarse, dispersándose completamente por todas partes o recogiéndose según un orden. ${ }^{08}$ Es fácil ver, por

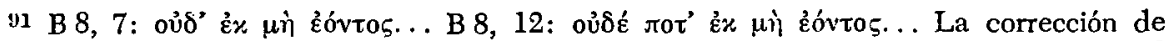
Kranz del ov' $\tau^{\prime}$ por oủ ', en B 8, 7, es pertinente. Parécenos que esto soluciona la dificultad

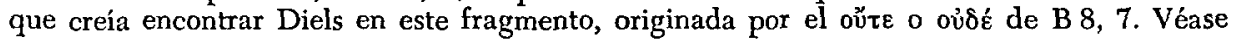
n. 63.

92 B 8, 12.

93 B 8, 5 .

94 Arist., Metaph., A, 5, 986b 27. Cf. B, 4, 1001a 29; phys., A, 3, 187a 6; Simpl., phys., 115, 11 (A 28); phys., 236, 8; Porf., in Simpl. phys., 116, 8; Alejandro, in Metaph., 44,10 .

95 Cf. Cornford, op. cit., p. 35.

965 Sin embargo, Aristóteles ya hubo de ver que la divisibilidad implicaba la pérdida de la unidad del ente. Cf. Arist., de gen. et corr., A, $8325 \mathrm{a} 3$.

97 B 8, 22.

98 B 4. Consideramos que vówı, en este texto ès un dativo instrumental unido a $\lambda \varepsilon v \tilde{\sigma \sigma \varepsilon,}$ al cual debe unirse también el ö $\mu \omega 5$. Es evidente que en el primer verso se alude al orden aparente, captado por los sentidos, donde parece reinar la multiplicidad, para escapar al cual es menester.no ver (de ahí el $\lambda_{\varepsilon} \tilde{v} \sigma \sigma \varepsilon$ ) con los ojos sensibles, sino con el pensamiento.

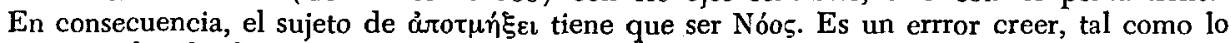
ha sugerido Th. Gompers, que su sujeto sea iò xєveóv. Véase Th. Gompers, Greek Thinkers, I, J. Murray, London, 1939; p. 553. 
consiguiente, que no hay nada que pueda impedirle el ser continuo. El ente sólo toca al ente. ${ }^{99}$ Su unidad queda así demostrada, puesto que la multiplicidad, como resultado de una génesis parcial o de una división, es imposible,

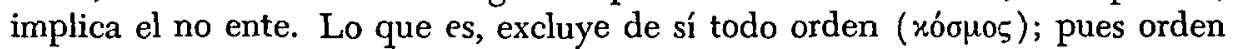
sólo puede haberlo donde haya multiplicidad. De hecho, no corresponde a ninguna realidad. Todo orden, como ya vimos, no puede ser más que un orden engañoso de palabras y nada más. ${ }^{100}$

Pero todavía se desprende una consecuencia más del hecho de que el ente sea ingenerado e imperecedero. Dado que no tiene principio ni fin, límites que implicarían un movimiento, un cambio generativo o destructivo, el ente es inmóvil (ảxivłrov). Génesis y destrucción, para Parménides, equivalen a un

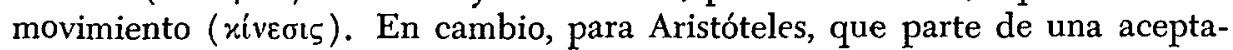
ción de la génesis y corrupción y, por ende, no las considera como un tránsito

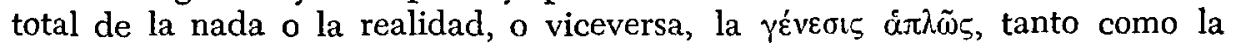

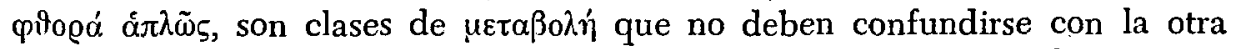
de sus clases, con la xiveol5. ${ }^{101}$ Las primeras se dan entre contradictorios, la segunda entre contrarios. Su distinción, por lo que se ve, es bien precisa dentro del pensamiento aristotélico. ${ }^{102}$ En todo caso, se trata de meras discrepancias terminológicas que no afectan lo esencial e irreductible de la doctrina parmenídea, surgida en otra circunstancia espiritual, más primitiva e ingenua, si así puede decirse, y con otras miras.

La generación y la destrucción, como posibilidades de que el ente exista y no exista $y$, por lo tanto, se mueva, vienen a quedar reducidas a meros nombres, sin más fundamento que la fuerza engañadora de los sentidos, al igual que ocurre, de modo más patente, respecto del "mudar de color brillante". ${ }^{103}$ Tan absurdo sería el querer adscribir al ente un principio o un cese, como el querer adscribirle un determinado y pasajero colorido.

A la negación de semejantes movimientos, Parménides agregará la negación del movimiento de lugar, o como él mismo nos dice, del "cambiar lugar".104 La demostración correspondiente, una de las más intrincadas del Poema, se basa íntegramente en la exclusión de todo lo que no sea el ente mismo, por cuanto ello equivaldría al no ente. En efecto, el cambio de lugar presupone implícitamente dos cosas distintas: el lugar y aquello que está en ese lugar. Esto, aplicado al ente, revela toda su incongruencia. Lo que es no puede estar en ningún lugar, en algo distinto de él o, lo que es igual, en el no ente. Perma-

99 B $8,25$.

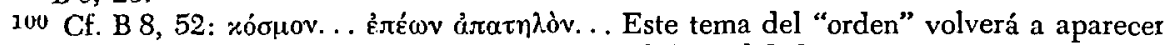
en el frag. 7,3 , de Meliso, donde se rebate su pretendida realidad.

101 Arist., phys., E, 1, 224b 35-225 9. Véase Diels, op. cit., p. 83.

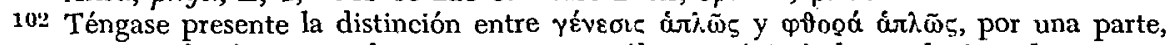

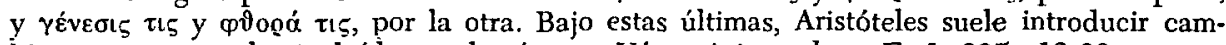
bios semeiantes a los incluídos en la xívnoıs. Véase Arist., phys., E, 1, 225a 12-20.

103 B 8, 38.

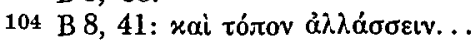




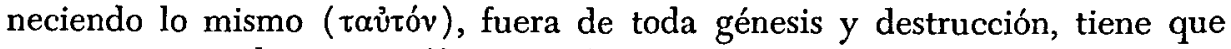
permanecer en lo mismo ( $\dot{\varepsilon} v \tau \alpha \hat{v} \tau \tilde{\imath} \mathrm{l}$ ), esto es, tiene que yacer en sí mismo

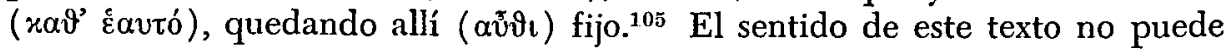
dejar lugar a dudas. Parménides se propone mostrarnos que el ente no puede yacer sino en sí mismo, puesto que suponer lo contrario significaría darle una cierta realidad al no ente. De aquí resulta inmediatamente que el ente no puede cambiar de lugar. No sólo es inmóvil, como nos lo dice la primera parte de este texto, por no generarse ni perecer, sino también porque no hay lugar que pudiera abandonar ni lugar hacia donde pudiera ir. Estas dos diferentes "especies" de movimiento se indican con toda claridad en los versos que hemos citado más arriba. Sin embargo, ha sido frecuente no caer en la cuenta de ello, principiando por los doxógrafos de la antigüedad. ${ }^{106}$ Que ésta sea su verdadera interpretación, lo atestiguan tanto la inmediata continuación del argumento, como el testimonio platónico en el Teeteto. ${ }^{107}$ Platón reproduce, en efecto, la misma argumentación del eleata, casi con su's mismas palabras. El ente uno

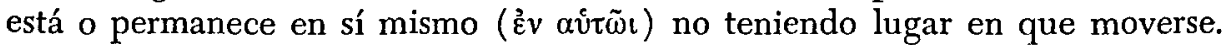
Argumentación que Meliso desenvolverá, introduciendo la negación del vacío, y a partir de la infinitud del ente; pero siempre, como ya veremos, basado en esta concepción de Parménides. ${ }^{108}$

Esta necesidad de yacer en sí mismo es, justamente, lo que impide que el ente se mueva; puesto que, para hacerlo, tendría que dejar de estar en sí mismo, o lo que es igual, tendría que rebasar los límites dentro de los cuales se conserva en sí mismo. Tales límites lo ciñen por todas partes. El ente no puede, por así decirlo, abandonarse por ningún lado, dejar de yacer en sí mismo para moverse, sea en una dirección o en otra. ${ }^{109}$ Esto sugiere ya de inmediato una figura limitada en todas direcciones, pero no por el espacio, puesto que no lo hay, sino por el hecho de no poder salir de sí, de no poder moverse; pues, por poco que el ente se moviera, dejaría de estar en sí mismo y se cambiaría en no ente. El más mínimo movimiento equivaldría a la pérdida de su integridad, a la desaparición de la "parte" que rebasara sus límites y, por ende, a su aniquilamiento, ya que el ente no puede carecer de nada, so pena de carecer de todo. ${ }^{110}$ El cambiar de lugar implica en último resultado, para Parmé-

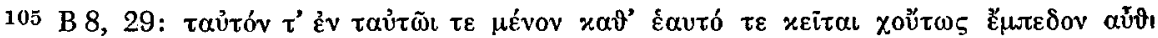
$\mu \varepsilon ́ v \varepsilon l$. (Permaneciendo lo mismo y en lo mismo, yace en si mismo, y de este modo permanece

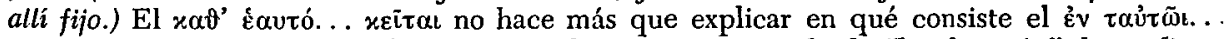
$\mu \varepsilon ́$ vov. Que esta última fórmula deba entenderse en este sentido de "localización", lo confirma

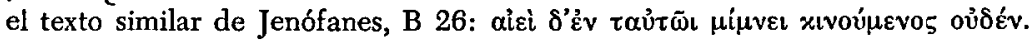

100 Véase, por ejemplo, Plutarco, adv. Colot., 13, p. 1114.

107 Plat., Teet., $180 \mathrm{e}$.

108 Meliso, B 7, 7. A este texto se refiere seguramente Platón en su testimonio ya citado. Véase n. 107.

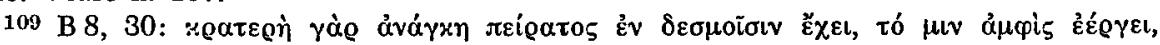

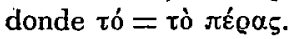
110 B 8, 33 . 
nides, un cambio más radical: el cambio de ente a no ente. Consecuentemente, lo que es debe quedar inmóvil, dentro de sus límites, justo porque no le es lícito ser incompleto. ${ }^{111}$ Esta serie de razonamientos no puede entenderse de otra manera. Suponer que en el fondo de todo esto se oculta un hilozoísmo es un error sin más fundamento que la pretendida prioridad teórica de Jenófanes sobre Parménides, que no es posible seguir sosteniendo hoy en día. ${ }^{112}$

Ahora bien, puesto que tiene un límite extremo, irrebasable en todos sus puntos, el ente está terminado por todos lados, sin posibilidad alguna de ser incompleto; ${ }^{113}$ ya que, semejante a la masa de una bien redonda esfera, es igual a partir del medio en todas direcciones. Esto viene a significar que el ente, dado ese límite, se extiende de modo uniforme, a partir de un punto medio, pues necesario es que no sea algo más por un lado o por otro, ni algo menos. ${ }^{114}$ La inmovilidad y la limitación, con todo lo que implican, se conjugan ahora con la homogeneidad y la continuidad de lo que es, a efecto de dejar establecido que el ente no puede carecer de nada y que, por tanto, es completo y está terminado por todos lados. No es posible, en primer término, que lo que no es pueda impedirle alcanzar la homogeneidad. ${ }^{115} \mathrm{El}$ no ente no está, por así decirlo, mezclado o revuelto con el no ente, tal como para los mortales ocurre en el mundo de la opinión, donde Luz y Noche, ente no ente, lo llenan todo. ${ }^{110}$ Por otra parte, lo que es no puede ser más aquí y menos allí de lo que es. ${ }^{117}$ En su seno no puede haber hiatos ni cortes. El ente está a salvo de toda violencia de ese género, de todo disgregamiento o corte. Es un todo inviolable, pues por todas partes es igual a sí mismo e impera del mismo modo en el límite de su perfección. ${ }^{118} \mathrm{El}$ ente es igual al ente y no carece de nada; por lo tanto, es inmóvil, no puede enajenarse, salir de sí, o lo que es lo mismo, rebasar los límites que le fija el yacer en sí y el ser completo.

El límite del ente no es, pues, un límite espacial. Entenderlo en tal forma chocaría con toda la doctrina de Parménides. Si el ente estuviera limitado

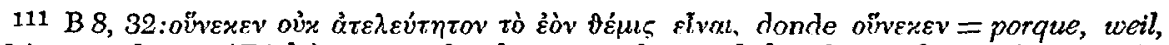
perchè y no darum (Diels), siguiendo el parecer de Fränkel. Cf. Simplicio, phys., $7: \dot{\omega} \xi$

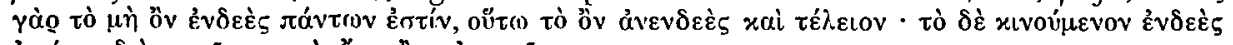

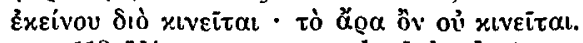

112 Véase, por ejemplo [Plut.], Strom., 4 [Eusebio, P. E., I, 8, 4. D. 580] (Jenófa-

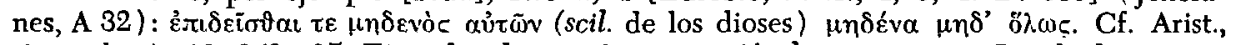
de caelo, A, 10, 379a 35. Ejemplos de esta interpretación lo constituyen Cornford, op. cit., pp. 42-43, y Zafiropulo, op. cit., passim.

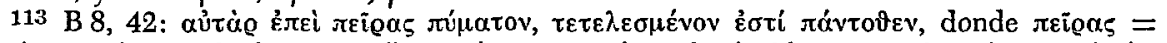

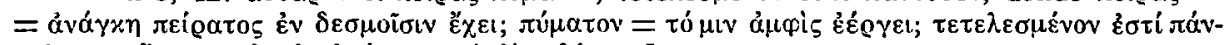

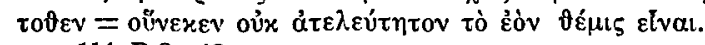

114 B 8, 43.

115 B $8,46$.

116 B $9,3$.

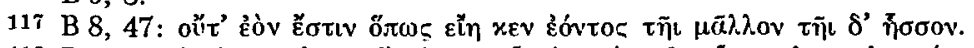

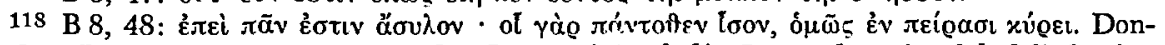
de: ol, reflexivo como en Hom., Od., II, 434 (Fränkel). La traducción del difícil xúg̨ı que propone Diels, op. cit., págs. 91-92, es ciertamente difícil de aceptar. 
espacialmente, más allá de él sólo podría encontrarse lo que no es él, el no ente. $\mathrm{El}$ absurdo de esto salta a la vista. Y no hubiera escapado a un pensador tan coherente como el eleata. Más bien, eso es precisamente lo que ha dado origen a esa interpretación tan aguda sobre el único "lugar" posible del ente, que, como hemos visto, se identifica con él. El ente es el "lugar" del ente y nada más puede serlo, a menos que se admita su negación como algo real. Con todo, el grueso de los historiadores de la filosofía ha creído que su interpretación justa era la de considerarlo como finito, en clara oposición con el ente intinito de Meliso. Aristóteles así parece haberlo entendido. ${ }^{119}$ Claro está que .

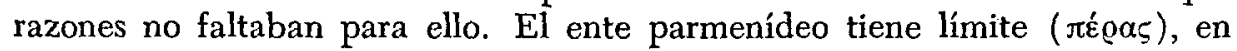

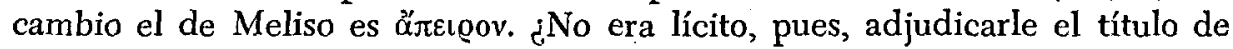
$\pi \varepsilon \pi \varepsilon \varrho \propto \sigma u \varepsilon ́ v o v$ en sentido espacial? El error consistió en no haber advertido que las teorías de Parménides y de Meliso no son parangonables en este aspecto. Para Parménides, la finitud o infinitud del ente no constituyen problema. Son algo en lo que no se le ocurre pensar. El hecho es obvio, por poco que reflexionemos en él. Para entender el enlace de la limitación con la homogeneidad $y$ continuidad de lo que es, no es necesario, para el modo de ver del eleata, el agregado de un espacio externo al ente mismo. Cierto es que su extensión uniforme no puede concebirse sino con un aspecto estereométrico, y ello es justamente lo que ha hecho posible aludir a su punto medio; pero eso es algo inherente a tò śóv, puesto que un espacio "externo", repetimos, equivaldría sin más al no ente. Sus límites no confinan con un espacio semejante. Todo espacio, si de él puede hablarse en la doctrina del eleata, es interno a lo que es.

Precisamente en este punto es donde entronca la concepción melisiana de la infinitud. Meliso, con más bagaje conceptual para aprehender una realidad "material" de este tipo, agregará a los atributos ya establecidos del ente uno más: el de la infinitud. Con ello no ha hecho sino ahondar en el sistema eleático y extraer de él todas sus consecuencias. Ese "espacio" interno vendrá a quedar especificado como algo de dimensiones infinitas y ya no meramente indefinidas, como en el caso de Parménides. Por otra parte, los limites del ente parmenídeo no han podido perturbar en lo más mínimo esta conclusión, supuesto que no son límites que marquen o deslinden una determinada porción finita del espacio. De aquí, justamente, Io indefinido de sus dimensiones. Si alguien hubiera interrogado a Parménides por ellas, éste habría quedado perplejo, puesto que, para él, decir que lo que es es limitado no era decir nada tocante a ellas. En este sentido, Meliso no remedia ninguna falla en la doctrina de su maestro, como es la opinión de muchos historiadores. ${ }^{120}$ Pero su mérito no es menor. Si Zenón es el defensor encarnizado, Meliso es la cumbre del eleatismo.

Por consiguiente, la esfera no viene a ser otra cosa que un símil poético,

119 Arist., phys., Г, 6, 207a 9.

120 Véase, por ejemplo, Th. Gompers, op. cit., p. 190. 
una metáfora, tendiente a evidenciar, con ayuda de la imaginación, la íntima relación en que están la homogeneidad y continuidad de lo que es con su ser completo. El ente es semejante ( $\dot{\varepsilon} v a \lambda$ i $x$ iov) a una esfera, pero no es una esfera. ${ }^{121}$ Así lo hubo de considerar ya en la antigüedad Simplicio, ${ }^{122}$ y así lo creen hoy en día numerosos investigadores. ${ }^{123}$ En realidad, la esfera no viene a ser más que el símbolo de la perfección del ente y no de su finitud. Como símbolo de la perfección, la encontramos muy frecuentemente a lo largo de la historia de la filosofía griega. Para Platón, el mundo es de forma esférica, por cuanto ésta es la figura más perfecta, la que comprende todas las figuras posibles y la más completamente semejante a sí misma. ${ }^{124}$ El cielo, para Aristóteles, es esférico, ${ }^{125}$ etc. Los ejemplos que podrían citarse son muy numerosos; pero, en un texto muy significativo de Empédocles, volvemos a encontrar la imagen de la esfera usada en un sentido que no puede ser espacial, por cuanto que lo que mienta es calificado de "totalmente infinito". ${ }^{120}$ Aquí,

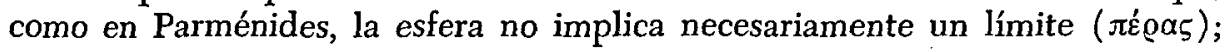
$\tan$ es así que aun lo infinito ( $\left.\alpha^{\prime} \pi \varepsilon ı \rho o v\right)$ puede recibir este nombre.

El ente es perfecto, limitado, no puede carecer de nada, pues nada podría impedírselo. Pero, al par, es completamente racional. Cosa que también viene a simbolizar la imagen de la esfera, de la rotundidad. La verdad sobre el ente es tan rotunda, metafóricamente hablando, como rotundo es el ente mismo. ${ }^{127} \mathrm{Al}$ pensamiento no puede escapar ninguna porción de la realidad, $\mathrm{y}$, en este sentido, es perfecto como su objeto; lo cual no es sorprendente, dados los lazos tan firmes que los unen. Todo esto, una y la misma imagen nos lo recalca.

5. $\dot{A}$ partir de esta teoría del ente, queda establecida, por paradójico que parezca, toda una concepción acerca del no ente. Lo que no es hubo de presentarse como inexpresable e impensable y, sin embargo, mucho es lo que se nos dice en torno a esta noción, a causa precisamente del peculiar tratamiento que se da al ente, enfrentándolo al no ente y dibujándolo sobre él. Es manifiesto que todos sus atributos hallan su fundamento último y su razón de ser

121 Calogero, op, cit., p. 27, seguido por Mondolfo, op. cit., p. 349, da a esto una interpretación dinámica con la que no estamos de acuerdo. El ente no es ciertamente una esfera; pero tampoco un infinito ampliarse en la forma homogéneamente finita de la esfera, como lo quiere Calogero. Esta interpretación toma demasiado literalmente el sentido dinámico del íveĩofar de B 8, 46.

122 Simpl,, phys., 146, 31.

123 Entre los principales, podemos citar a Natorp, Kinkel, Herbertz, Coxon, Joel y Gigon.

124 Plat., Timeo, 33b-c.

125 Arist., de caelo, $\mathrm{B}, 4,287 \mathrm{a}$ 11-14.

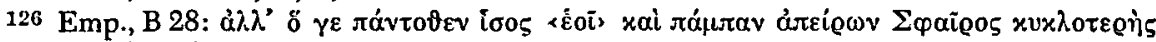

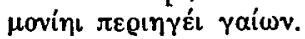

127 B 1, 29. Ya A. H. Coxon, "The philos. of Parm.", Classical Quarterly, XXX, p. 140, hablaba de la esfera en estos términos: "a simile illustrating the possibility of rational thinking". 
en la inexistencia de lo que no es. La validez de ellos se finca, en último término, en la fuerza probatoria que emana de tal inexistencia. En este aspecto, el no ente desempeña, en el pensamiento de Parménides, el papel de un instrumento metodológico, cuya función es ayudar a demostrar, por reducción al absurdo, que el ente es y tiene tales y cuales características; puesto que un ente considerado, ya sea como miembro de una multiplicidad de cosas, ya como sujeto a la generación y al cambio, etc., supone la admisión velada del no ente. Teóricamente, por lo tanto, tò $\mu$ in ơv sería lo único que haría posible un mundo donde se incluyeran esos factores como formando parte de la realidad. Históricamente, tal será el camino que seguirá el desarrollo de esta noción, aunque según la doctrina del eleata todo eso no constituya sino un orden vacuo de palabras enmascaradoras, y por ello engañosas, del absurdo que ahí se encierra. Sin embargo, en lo futuro, parece como si esas palabras trataran de reivindicar a toda costa sus derechos frente al eleatismo. ${ }^{128}$ Parece como si la Vía de la Opinión se rebelara contra el puesto que le ha sido asignado por esta concepción tan radical y pugnara por conquistar un sitio en el reino de la Verdad. Llegado el momento, podremos advertir cómo, en numerosos casos, toma un gran incremento la reacción contra las tesis eleáticas sobre el no ente. Esta especie de mordaza, con la que se acallaban las protestas del mundo de la experiencia, será por fin arrojada violentamente a un lado. Nuevas concepciones sobre el no ente vendrán a substituir a la eleática, y su principal autor caerá repetidas veces víctima de ese "parricidio" de que nos habla Platón en su Sofista. ${ }^{129}$

Ahora bien, el no ente no sólo puede ser considerado bajo este aspecto metodológico, sino también bajo otro, derivado de lo que en última instancia sea tò éóv. En efecto, como es bien sabido, el ente de Parménides ha sido interpretado desde hace mucho como algo material o corpóreo, por historiadores de la talla de Zeller, Baeumker, Diels, Schaaf, etc. De ser esto así, ello querría decir consecuentemente que lo que no es viene a identificarse con lo inmaterial o incorpóreo, con lo vacío de cuerpo o materia. Semejante punto de vista parécenos que lleva la cuestión muy lejos y no puede ser captado sino con muchas reservas, aunque parta de un hecho real e incontrovertible. Parménides, como es fácil de ver, no distingue una realidad corpórea de otra que no lo sea. Ni pudo haberlo hecho. La misma terminología le faltaba para ello. La palabra $\sigma \tilde{\omega} \mu \alpha$ que podemos encontrar en Homero, no se usa primitivamente para nombrar al cuerpo en general, sino al cuerpo humano que ha sido abandonado por el alma, al cadáver. ${ }^{130}$ En Hesíodo se da ya la acepción más

128 Gorgias, en rigor, no puede considerarse como formando parte de este movimiento. Las razones de ello son evidentes. Basta el comparar los títulos de una de las más

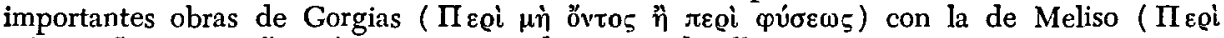

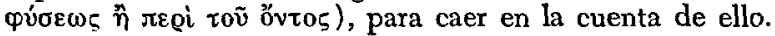

129 Plat., Sof., 241d.

130 Véase, por ejemplo, Hom., Il., 3, 23; 7, 79. 
amplia de cuerpo humano viviente; ${ }^{131}$ misma que le dará Parménides, ya que no puede ser dudoso que Caelius Aurelianus, a quien debemos la conservación del fragmento donde la palabra se cita, haya vertido al latín $\sigma \tilde{\omega} \mu \alpha$ con corpus. ${ }^{132}$ Por otra parte, el término v̋ln se encuentra en idénticas condiciones. Tal como se puede ver en la Ilíada y la Odisea, v̌n $\eta$ sirve para designar tanto los bosques como los materiales que de ellos se pueden sacar, sea leña para las hogueras, o madera para las construcciones. ${ }^{133}$ Sentidos que la palabra conservará durante toda la época clásica hasta Aristóteles, ${ }^{134}$ descontando su uso metafórico, obra de los retóricos y logógrafos, como "tema" o "materia" de un discurso, o su uso en la medicina de los tiempos de Alcmeón, como "componente" del cuerpo vivo.

Con todo, la tarea que lleva a cumplimiento Parménides no nos entrega, como fruto último, un ente con las características que se suelen adscribir a lo puramente ideal. Todos los pensadores que lo antecedieron han reflexionado. sobre las cosas, sobre tà óvta. Lo que distingue al eleata de ellos es que éste ha encauzado su pensamiento, no ya sobre una multiplicidad de ellas, sino sobre la Cosa, sobre el Ente. Puesto a pensar en qué atributos o características convengan a las cosas, se encuentra con que no se trata de cosas, sino de Cosa, y que ésta tiene caracteres en franca oposición con un mundo de cambio y multiplicidad. La Cosa, a diferencia de las cosas, no cae dentro del ámbito de la experiencia. No es objeto de la sensación, sino, por el contrario, objeto exclusivo del pensamiento. ${ }^{135}$ Pero, a pesar de todo, sigue conservando atributos que sólo pueden convenir a las cosas. Es homogénea, continua. Rasgos que requieren ineludiblemente, para ser entendidos cabalmente, la base de una cierta extensión propia de tà óv $\tau \alpha$, o como diríamos hoy, de lo corpóreo. Parménides se queda, valga la expresión, con las "cualidades primarias" de toda cosa, con la Luz, y lo que ésta implica, del orden de la opinión, en tanto que rechaza las "cualidades secundarias", entre las que se cuentan no sólo el "color brillante", sino también la multiplicidad y el cambio, con todo lo que arrastran consigo. La única realidad pierde estos caracteres, pero conserva los suficientes para seguir siendo una cosa. Esto es, sin duda alguna, lo que ha motivado el juicio de Aristóteles sobre todos los pensadores primitivos. Para éstos, en cuanto que identifican la ov̉oía y tò öv con el cuerpo ( $\sigma \tilde{\omega} \mu \alpha)$, los principios de los cuerpos vienen a ser los principios del ente. ${ }^{136}$ Juicio que, en rigor,

131 Hes., Los trab. y los días, 540.

132 B 18, 3 y 4 .

133 Hom., Il., 2, 455; 11, 155; 15, 273; 15, 606; 16, 766; 20, 491; 23, 127; 24, 784; Od., 5,$257 ; 5,470 ; 6,128 ; 9,234 ; 14,353 ; 17,316$. Cf. Emile Boisacq, Dict. étymologique de la langue grecque, Heidelberg-París, $2^{\mathrm{a}}$ ed., 1923; p. 1000.

134 Platón inclusive toma el término en estos sentidos. Véase, por ejemplo, Pol., 272a; Fil., 54c; Leyes, 761c y 849d. En Timeo, 69a, v̛̉n significa "material de construcción" y no "materia", como muchas veces se ha afirmado.

135 F.n este punto no tiene razón Aristóteles, Metaph., $\Gamma, 5,1010 \mathrm{a}$ 1, cuando nos dice:

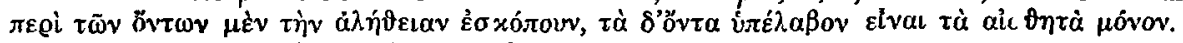

136 Arist., Metaph., B, 5, 1002a 8. 
aplicado a Parménides, no tiene más apoyo que el aspecto de cosa que aún guarda tò cóv, dada su extensión y uniformidad. Las mismas Ideas de Platón parecen arrastrar todavía un carácter parecido en la famosa objeción que Parménides, en el diálogo que lleva su nombre, dirige al joven Sócrates en contra de la participación. ${ }^{137}$

El no ente se nos revela, en consecuencia, como la no Cosa, como lo único capaz de escindir la continuidad extensiva del ente. La distancia que lo separa de ser considerado como el espacio vacío de cuerpo es bien poca. El atomismo ha de realizar de hecho esta identificación a causa, precisamente, de la necesidad en que se ve de tener que aceptar el vacío como condición ineludible para que se dé el movimiento. De aquí que el no ente cobre, en el pensamiento de Demócrito, un carácter tan paradójico. También el no ente existe: es el vacío. Lo que es se ha hecho coincidir ya expresamente con el cuerpo, y lo que no es con lo incorpóreo. Pero esto no sucede hasta entonces. Puede verse, por lo tanto, todo lo que media para que Parménides, dada su tajante negación de lo que no es, haya llegado a una concepción corporalista del ente y del no ente. Más justo es afirmar que, para él, el ente es una Cosa, en cuanto encierra lo que hemos denominado latu sensu las "cualidades primarias" de las cosas, la Cosa, el preludio de lo que con el atomismo será lo corpóreo, en tanto que el no ente, la negación inexistente de lo que es continuo y extenso, es la anticipación de lo incorpóreo. De un verdadero rango ontológico, entendida esta palabra en la plenitud de su sentido, el ente queda aún separado por un rasgo esencial. Considerado desde un punto de vista más elaborado, puede decirse con Eudemo (Simpl., phys., 115, 11), fiel intérprete del pensamiento de Aristóteles sobre este punto, que el ente de Parmé-

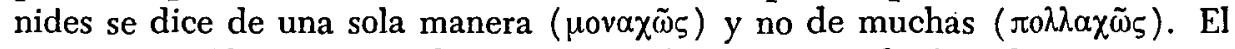
ente parmenídeo no es analógico, sino unívoco. La analogía del ser es, justamente, el rasgo nuevo que adquirirá cuando ya sea sujeto de un tratamiento plenamente ontológico. Y lo mismo ocurre con el no ente. El asunto, como se ve, es muy importante. Sin embargo, nos contentaremos con apuntarlo aquí, dejando para más adelante su tratamiento con la amplitud de detalle que requiere. Por lo pronto, volviendo al no ente, podemos decir que su papel se limita al campo de lo gnoseológico, en el cual la función que le asigna el eleata es allanar y despejar la vía de la verdad de todo elemento extraño. Esta labor epistemológica constituye la gran hazaña de Parménides. "Damit-como tan acertadamente nos dijera Nietzsche-vollzog er die überaus wichtige, wenn auch noch so unzulängliche und in ihren Folgen verhängnissvolle erste Kritik des Erkenntnissapparats." 138

Adolfo García Díaz

137 Plat., Parm., 131a-e.

138 Nietzsche, Die Philosophie im tragischen Zeitalter der Griechen, Gesammelte Werke, IV, Musarion Verlag, München, 1921; p. 197. 